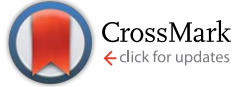

Cite this: RSC Adv., 2017, 7, 9680

Received 1st January 2017

Accepted 23rd January 2017

DOI: 10.1039/c7ra00021a

rsc.li/rsc-advances

\section{Effect of samarium and vanadium co-doping on structure, ferroelectric and photocatalytic properties of bismuth titanate $\uparrow$}

\author{
E. Venkata Ramana, ${ }^{* a}$ N. V. Prasad, ${ }^{* b}$ David Maria Tobaldi, ${ }^{c}$ Janez Zavašnik, $^{d}$ \\ M. K. Singh, ${ }^{e}$ María Jésus Hortigüela, ${ }^{e}$ M. P. Seabra, ${ }^{C}$ G. Prasad $^{b}$ and M. A. Valente ${ }^{a}$
}

We performed a systematic analysis of the structure, ferroelectric and photocatalytic activities of Sm and V codoped $\mathrm{Bi}_{4} \mathrm{Ti}_{3} \mathrm{O}_{12}$ (SBVT) ceramics. The formation of 3-layered Aurivillius structure and chemically induced strain of SBVT were analyzed by SEM and HRTEM studies. From the results of structural refinements, temperature dependent XRD and Raman spectra we found that SBVT has a distorted orthorhombic structure and transforms to tetragonal in the temperature range of $475-600{ }^{\circ} \mathrm{C}$. Raman modes of $\mathrm{Bi}$ sites experience the phase transition earlier compared to torsional bending modes of $\mathrm{BO}_{6}$ octahedra. From the results of polarization and piezoelectric strain measurements, we found that SBVT exhibits superior ferroelectric characteristics as well as improved $\mathrm{S}_{33}\left(0.02 \times 10^{-3}\right)$ compared to other rare-earth doped $\mathrm{Bi}_{4} \mathrm{Ti}_{3} \mathrm{O}_{12}$ materials reported in the literature. SBVT exhibited fatigue endurance up to $10^{8}$ switching cycles. Such

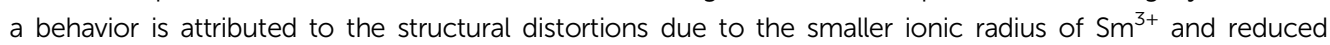
oxygen vacancies. Local piezoresponse measurements demonstrated imprint characteristics of ferroelectric domains. Furthermore, we assessed the photocatalytic (PC) activity of SBVT - for the first time - in the gassolid phase, monitoring the degradation of nitrogen oxides (i.e. $\mathrm{NO}+\mathrm{NO}_{2}$ ). Results demonstrated that SBVT was photocatalytically active in the solar spectrum, being able to degrade $\mathrm{NO}_{x}$ at ppb level concentration, and exhibited a very stable PC activity (five consecutive PC runs), proving itself suitable for reuse.

\section{Introduction}

Bismuth layered perovskites of the Aurivillius family have received a lot of attention because of their potential applications in non-volatile memory, electro-optic devices, and microelectromechanical systems. ${ }^{\mathbf{1 - 4}}$ Aurivillius phases are characterized by the formula: $\left(\mathrm{Bi}_{2} \mathrm{O}_{2}\right)^{2+}\left(\mathrm{A}_{m-1} \mathrm{~B}_{m} \mathrm{O}_{3 m+1}\right)^{2-}$, where $\mathrm{A}$ - and $\mathrm{B}$-sites are in cuboctahedral and octahedral coordination, respectively. The integer $m$ represents the number of octahedral layers., ${ }^{5,6}$ The spontaneous polarization for evenlayered Aurivillius phases is along the $a$-axis while for oddlayered compounds like $\mathrm{Bi}_{4} \mathrm{Ti}_{3} \mathrm{O}_{12}$ (BTO), it is within the $a-c$

${ }^{a}$ I3N-Aveiro, Department of Physics, University of Aveiro, Aveiro-3810 193, Portugal. E-mail:venkataramanaesk@rediffmail.com

${ }^{b}$ Materials Research Laboratory, Department of Physics, Osmania University, Hyderabad-500 007, India.E-mail: nvp_phys@osmania.ac.in; nvp1969@rediffmail. com

${ }^{c}$ Department of Materials and Ceramics Engineering/CICECO, University of Aveiro, Aveiro-3810 193, Portugal

${ }^{d} J o z ̌$ ef Stefan Institute, Centre for Electron Microscopy and Microanalysis, Jamova cesta 39, 1000 Ljubljana, Slovenia

${ }^{e}$ Centre for Mechanical Technology and Automation (TEMA), Department of Mechanical Engineering, University of Aveiro, Aveiro-3810 193, Portugal

$\dagger$ Electronic supplementary information (ESI) available. See DOI: 10.1039/c7ra00021a plane, with the major polarization along the $a$-axis. BTO with monoclinic structure $\left(B_{1} a_{1}\right)$ has been regarded as a promising candidate for memory devices due to its high Curie temperature $\left(T_{\mathrm{C}} \sim 675{ }^{\circ} \mathrm{C}\right)$ and large spontaneous polarization $\left(P_{\mathrm{S}} \sim 50 \mu \mathrm{C}\right.$ $\mathrm{cm}^{-2}$ ). However, it was found that rare-earth (such as La and Nd) doped BTO films are fatigue-free compared to BTO. Although tremendous research is being made on La doped BTO, the plausible mechanism of La role is required for the complete commercialization point of view. In addition to rare-earth doping, substitution of $\mathrm{V}^{5+}$ for $\mathrm{Ti}^{4+}$ helps to enhance dielectric and ferroelectric properties due to the increased rattle space inside the oxygen octahedra. ${ }^{7,8}$ In view of improved ferroelectric properties in A- and B-site doped BTO new rare-earth doped materials are being studied for their applications in memory.

Apart from the use in non-volatile memories, BTO based materials have recently attracted the attention of the scientific community for photovoltaic (PV) and photocatalytic (PC) applications. Aurivillius materials are considered as alternatives to conventional $\mathrm{TiO}_{2}$ - based photo catalysts, ${ }^{9}$ mainly because, in these materials, bismuth shifts the absorption into the visible range thanks to hybrid $\mathrm{Bi} 6 \mathrm{~s}-\mathrm{O} 2 \mathrm{p}$ orbitals in the valence band $^{\mathbf{1 0}}$ and an extended separation of the photo-generated pair $\mathrm{e}^{-} / \mathrm{h}^{+} .^{11}$ BTO films grown on FTO substrate by a sol-gel technique, were reported to show a maximum PV conversion efficiency of $0.00026 \% .{ }^{12}$ In a recent study $\mathrm{Bi}_{3.25} \mathrm{La}_{0.75} \mathrm{Ti}_{3} \mathrm{O}_{12}$ thin 
film grown on p-type silicon with energy bandgap of $3.8 \mathrm{eV}$ was found to exhibit strong visible-light photovoltaic effect with high photoresponsivity. ${ }^{13}$ He et al. ${ }^{14}$ reported a strong photoresponse and photovoltaic performance for BTO/FTO thin films that can be modulated either by applying different bias voltages or through different poling states. ${ }^{14}$ Chen et al. ${ }^{15}$ in a recent study showed that BTO nano-sheets exhibited $79.2 \%$ of photo degradation efficiency of rhodamine B under 90 min of sunlight irradiation, larger than that of conventionally calcined BTO. Cao et al. ${ }^{16}$ reported that $\mathrm{BTO} / \mathrm{TiO}_{2}$ heterostructures exhibit higher degradation rate of rhodamine $\mathrm{B}(\mathrm{RhB})$ than the unmodified $\mathrm{TiO}_{2}$ submicron fibers under visible light. Such an effect was attributed to the extended absorption in the visible light region resulting from the BTO nano-sheets and the effective separation of photo generated carriers driven by the photo induced potential difference at the junction. Hou et al. ${ }^{17}$ reported the strong PC activity for a $\mathrm{p}-\mathrm{n}$ junction photocatalyst of BTO nanofibers-BiOI nano-sheets.

In view of above reports it is understood that PC applications of BTO is still an emerging field. However, most of the reported literature dealt with BTO and PC activity uses organic dyes as pollutants to be degraded in the liquid-solid phase. ${ }^{18-22}$ On the contrary, in this research, modified BTO is used to degrade nitrogen oxides $\left(\mathrm{NO} \& \mathrm{NO}_{2}\right)$ that are amongst the major atmospheric pollutants (both indoor and outdoor), being harmful to human being: ${ }^{23}$ and responsible for photochemical smog and acid rain $;^{\mathbf{2 4 , 2 5}}$ indeed, this is the first research of its kind to use BTO as a PC material working in the gas-solid phase against such harmful pollutants.

Based on the above salient work carried out on photocatalytic activity and rare-earth doped BTO for memory we synthesized Sm and V doped BTO ceramics. The chosen composition was $\mathrm{Sm}_{0.75} \mathrm{Bi}_{3.25} \mathrm{Ti}_{2.9625} \mathrm{~V}_{0.03} \mathrm{O}_{12}$ (SBVT). We performed detailed structural studies by in situ X-ray diffraction, Raman spectroscopy and transmission electron microscopy. The photocatalytic activity (PCA) of SBVT material was assessed for the first time in the gas-solid phase, monitoring the degradation of nitrogen oxides. Results showed that SBVT material was photocatalytically active in the solar spectrum.

\section{Experimental}

SBVT ceramics were synthesized by the conventional solid state reaction method. High-purity (99.9\%) starting materials $\mathrm{Bi}_{2} \mathrm{O}_{3}$, $\mathrm{Sm}_{2} \mathrm{O}_{3}, \mathrm{TiO}_{2}$ and $\mathrm{V}_{2} \mathrm{O}_{5}$ were mixed in stoichiometric ratio and milled for $12 \mathrm{~h}$ in ethanol media. The resulting slurry was dried and calcined at $900{ }^{\circ} \mathrm{C}$ for 2 hours. The powder obtained was again milled for $24 \mathrm{~h}$ and pressed under cold isostatic conditions, at $200 \mathrm{MPa}$, into cylindrical discs with 10 and $25 \mathrm{~mm}$ diameter. Final sintering was carried out at $1050{ }^{\circ} \mathrm{C}$ for 4 hours.

The crystal structure of the specimens was analyzed using the X-ray diffraction (XRD). Prior to the measurements, ceramic discs were powdered and annealed at $400{ }^{\circ} \mathrm{C}$ for $1 \mathrm{~h}$ to release strains. The data for structural characterization were collected using a Phillips X-ray diffractometer equipped with a fast RTMS detector and graphite monochromated $\mathrm{Cu} \mathrm{K}_{\alpha}$ radiation source ( $45 \mathrm{kV}$ and $40 \mathrm{~mA}, 2 \theta$ range of $5-110^{\circ}$, a virtual step scan of $0.01^{\circ}$ and virtual time per step of $798 \mathrm{~s}$ ). Rietveld refinements on the full profile fitting of the XRD patterns were accomplished using the GSAS-EXPGUI software suite. ${ }^{\mathbf{2 6}, 27}$ High temperature XRD (HTXRD) scans, in the $2 \theta$ range $10-80^{\circ}$, were done in the temperature range $22-700{ }^{\circ} \mathrm{C}$, operated with an accuracy of \pm 1 $\mathrm{K}$ using a Pt-Rh thermocouple directly attached to the sample holder. Raman spectroscopic measurements were made using a micro-Raman spectrometer (Horiba Jobin Yvon) with a $532 \mathrm{~nm}$ excitation laser, an edge filter for Rayleigh line rejection, and a CCD detector. The laser was focused on the sample to a spot size of $\sim 2 \mathrm{~mm}$ using a $50 \times$ objective lens in the temperature range 296-500 K, using a Linkam TC91 stage (Linkam Scientific Instruments Ltd., UK).

Surface morphology was evaluated by scanning electron microscopy (SEM, VEGA 3, Tescan). The structure and chemistry of the samples were studied using a $200 \mathrm{kV}$ transmission electron microscope (TEM; JEM-2100, Jeol Inc., Japan) equipped with $\mathrm{LaB}_{6}$ filament and energy-dispersive X-ray spectrometer (EDS). The micrographs were recorded with high-resolution slow-scan CCD camera (Orius DC1000, Gatan Inc.). Samples were scratched from the sintered disc and directly transferred on commercially available $\mathrm{Cu}$ grids (200 mesh $\mathrm{Cu}$ holey carbon, SPI Supplies/Structure Probe, Inc.) without dispersing in water, to avoid further alteration of the samples.

For electrical measurements gold electrodes were sputtered on polished ceramic specimens. Polarization-electric field hysteresis loops were measured using the hysteresis loop tracer TF-Analyzer (aixACCT). The dependence of longitudinal strain $(S)$ on electric field $(E)$ was measured at a frequency of $0.1 \mathrm{~Hz}$ in a silicone oil bath using a linear variable differential transformer. Dielectric measurements were performed using HP $4194 \mathrm{~A}$ analyzer in the frequency range $(100 \mathrm{~Hz}$ to $1 \mathrm{MHz})$ from room temperature to $600{ }^{\circ} \mathrm{C}$. Local piezoresponse was visualized using a commercial scanning probe microscope (Ntegra Prima, NT-MDT) equipped with an external lock-in amplifier (SR 830, Stanford Research) and a function generator (Yokogawa, FG 120). Here, we used commercial phosphorus doped Si probes (NANOSENSORS) with a radius of curvature $R<10 \mathrm{~nm}$, resonance frequency $13 \mathrm{kHz}$ and spring constant $(k)=0.2 \mathrm{~N} \mathrm{~m}^{-1}$.

$\mathrm{X}$-ray photoelectron spectra (XPS) were acquired in an ultrahigh vacuum (UHV) system with a base pressure of $2 \times 10^{-10}$ mbar equipped with a hemispherical electron energy analyzer (SPECS Phoibos 150), a delay-line detector and a monochromatic $\mathrm{Al} \mathrm{K}_{\alpha}(1486.74 \mathrm{eV}) \mathrm{X}$-ray source. High resolution spectra were recorded at normal emission take-off angle and with a pass-energy of $20 \mathrm{eV}$. For XPS measurements the powder sample was diluted in milli-Q water and a thin film was deposited on a silicon wafer by drop coating. Afterwards it was annealed under UHV conditions at approximately $400 \mathrm{~K}$ to remove surface contamination and water. $\mathrm{C}$ 1s spectrum was measured as reference for binding energy (BE) correction. The main peak of $\mathrm{C} 1 \mathrm{~s}$ spectrum, assigned to hydrocarbons from adventitious contamination, was referenced to $285.0 \mathrm{eV}$.

Diffuse reflectance spectroscopy (DRS) was used to investigate the optical behavior of the synthesized SBVT specimen, and to obtain information of the apparent optical bandgap $\left(E_{\mathrm{g}}\right)$ of the specimen, as this is a key-point in photocatalytic 
applications. Spectra were acquired in reflectance mode using a Shimadzu UV 3100 (JP) spectrometer, equipped with an integrating sphere made of $\mathrm{BaSO}_{4}$, in the UV-Vis range (850-250 $\mathrm{nm}$ ), with $0.2 \mathrm{~nm}$ resolution, using Spectralon ${ }^{\circledR}$ as white reference material.

The specific surface area (SSA) was evaluated by the Brunauer-Emmett-Teller (BET) method (Micromeritics Gemini 2380 , US) using $\mathrm{N}_{2}$ as the adsorbate gas, on samples degassed at $120{ }^{\circ} \mathrm{C}$. Pore volume (desorption cumulative pore volume, DCPV) and pore size distribution were estimated through the Barrett-Joyner-Halenda (BJH) method.

Photocatalytic activity tests were assessed in the gas-solid phase monitoring the abatement of nitrogen oxides (i.e. NO + $\mathrm{NO}_{2}=\mathrm{NO}_{x}$ ), that are amongst the major atmospheric pollutants. $^{25,28}$ The reactor employed worked in continuous conditions and has been previously described in detail by the authors. ${ }^{29,30}$ It is composed of a stainless steel cylinder $(35 \mathrm{~L}$ in volume); its top was sealed and covered with a Pyrex glass window to allow the light to reach the photocatalyst placed inside it. The solar lamp light source (Osram Ultra-Vitalux, 300 W) was placed $50 \mathrm{~cm}$ above the photocatalyst, so as to have a light intensity entering the reactor, and reaching the surface of the photocatalyst, equal to $8 \mathrm{~W} \mathrm{~m}^{-2}$ in the UVA range (315$400 \mathrm{~nm})$, and $50 \mathrm{~W} \mathrm{~m}^{-2}$ in the visible-light range (400-800 $\mathrm{nm}$ ) values measured with a radiometer, Delta OHM, HD2302.0 (IT), equipped with visible and UVA probes. Samples were prepared in the form of a thin layer of powder, with a constant mass $(\sim 0.10 \mathrm{~g})$, and thus approximately constant thickness, in a $6 \mathrm{~cm}$ diameter Petri dish (irradiated surface $\sim 28.3 \mathrm{~cm}^{2}$ ). The tests were performed at $27 \pm 1{ }^{\circ} \mathrm{C}$ (temperature inside the reactor) with a relative humidity $(\mathrm{RH})$ of $31 \%$. These parameters controlled by a thermocouple that was placed inside the chamber, and a humidity sensor placed in the inlet pipe remained strictly stable throughout the tests. The outlet concentration of the pollutant gas was measured using a chemiluminescence analyzer (AC-31 M, Environment SA, FR). After having placed the photocatalyst inside the reactor and covered the glass window, the inlet gas mixture (prepared using cylinders with synthetic air and $\mathrm{NO}_{x}$ gas) was allowed to flow until it reached a stable concentration of $200 \mathrm{ppb}$ (two mass flow controllers were used to prepare a mixture of air with this concentration of $\mathrm{NO}_{x}$ ). Once the desired concentration of 200 ppb was reached and stabilized inside the reactor, the window glass was uncovered, the lamp turned on, and the photocatalytic reaction was presumed to start. Control photolysis experiment was assessed prior to run a real photocatalytic test, and this proved to be negligible, as reported in Fig. S1. $\dagger$ The photocatalytic efficiency was evaluated as the ratio of the removed concentration of $\mathrm{NO}_{x}$, and the conversion rate (\%) of the initial $\mathrm{NO}_{x}$ concentration was calculated as:

$$
\mathrm{NO}_{x} \text { conversion } \%=\frac{\left(\mathrm{NO}_{x}\right)_{\mathrm{O}}-\left(\mathrm{NO}_{x}\right)_{\mathrm{S}}}{\left(\mathrm{NO}_{x}\right)_{\mathrm{O}}} \times 100
$$

where $\left(\mathrm{NO}_{x}\right)_{\mathrm{O}}$ and $\left(\mathrm{NO}_{x}\right)_{\mathrm{S}}$ are the initial and the $\mathrm{NO}_{x}$ concentration after a certain irradiation time. ${ }^{31}$ The SBVT specimen was irradiated for $60 \mathrm{~min}$, and the photocatalytic tests were repeated for a total of five times, using the very same sample and with the same protocol as the first test, with the aim of checking the repeatability, recyclability and photo stability of the prepared photocatalyst.

\section{Results and discussion}

Fig. 1 shows the XRD $\theta-2 \theta$ scan of SBVT ceramic. The synthesis protocol resulted in high purity Aurivillius phase whose reflections can be well-indexed to the BTO with $B 2 c b(41)$ space group $^{32}$ despite some minor shifting, overlapping and intensityinconsistency. In order to find the effect of simultaneous Sm and V doping at A and B sites of BTO we performed Rietveld refinement on full profile fitting of the XRD patterns, accomplished using the GSAS-EXPGUI software suite. ${ }^{26}$ The starting atomic parameters for the orthorhombic BTO, described by the space group (SG) $B 2 c b$, were taken from the previous report of Hervoches and Lightfoot. ${ }^{32}$ The following parameters were refined: scale-factors and zero-point; the background profile was modelled using a tenth order shifted Chebyshev polynomial function; unit cell parameters and sample displacement effects. The profile was modelled using a pseudo-Voigt function and one Gaussian $\left(G_{\mathrm{W}}\right)$ and two Lorentzian $\left(L_{\mathrm{X}}\right.$ and $\left.L_{\mathrm{Y}}\right)$ terms, as well as peak correction for asymmetry were used to model it. Moreover, preferred orientation along [001] was also refined, adopting the March-Dollase approximation. ${ }^{33}$ Atomic positions and isotropic displacement parameters $\left(U_{\text {iso }}\right)$ were refined too; the sum of the occupancies of $\mathrm{Bi}$ and $\mathrm{Sm}$ was constrained to the unity in all the refinements. Furthermore, the same atomic positions and $U_{\text {iso }}$ were given to these two atoms, and restrained to be identical. As per $\mathrm{Ti}$ and $\mathrm{V}$, this latter atom was not considered in the structural refinement, because of its tiny amount in the BTO, and also because it is difficult to differentiate between $\mathrm{Ti}$ and $\mathrm{V}$ due to their similar scattering factors. Consequently, it has to be stressed that the refined titanium atomic positions, $U_{\text {iso, }}$ and occupancies, are actually the sum of

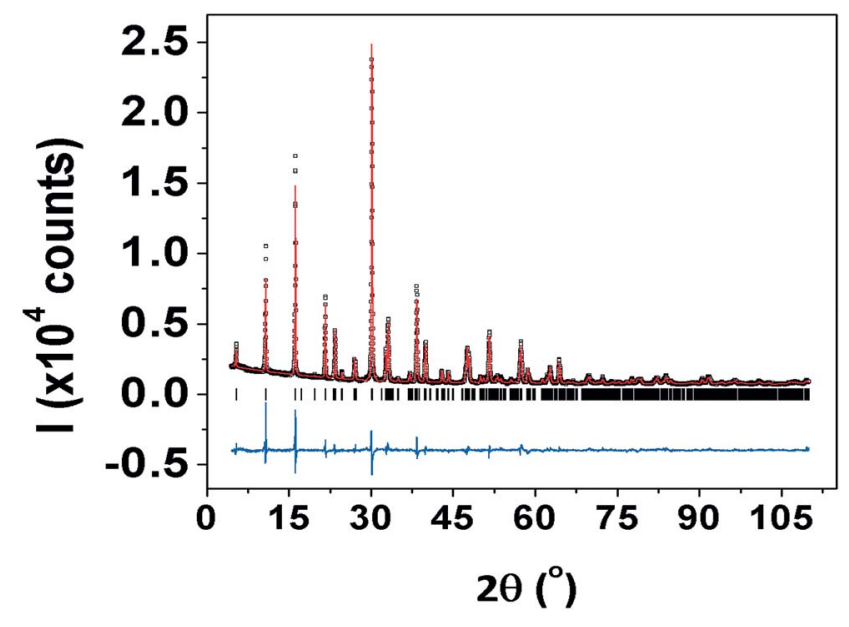

Fig. 1 Rietveld graphical output of SBVT. The black open squares represent the observed pattern, the continuous red line represents the calculated pattern, and the difference curve between the observed and calculated profiles is given by the blue continuous line plotted below. The positions of the reflections are indicated by the small black vertical bars. 
Ti plus V. Once the bond lengths and bond angles were calculated from the listing of distances and bond angles from GSAS, they were used to obtain a $3 \mathrm{D}$ rendering of the orthorhombic phase, via the VESTA software package. ${ }^{34}$ Also, the distortion index $(D)$, quadratic elongation $(\mathrm{QE})$ and bond angle variances (BAV) of the $\mathrm{TiO}_{6}$ octahedral sites in the orthorhombic phase were calculated, according to the formalisms of Baur, ${ }^{35}$ and Robinson et al. ${ }^{36}$ respectively. The unit cell parameters, unit cell volume, Rietveld agreement factors and crystal structural data are listed in Tables 1-3.

The refined lattice parameters, as listed in Table 1 , are $a=$ 5.4149(2) $\AA, b=5.3974(2) \AA, c=32.8194(7) \AA$ and volume of 959.19(4) $\AA^{3}$ respectively. As compared to the undoped BTO the unit cell exhibited a shrinkage $(0.542 \%, 0.21 \%, 0.07 \%$ and $0.82 \%$ decrease in $a, b, c$ and volume respectively). This can be attributed to the smaller atomic radius of $\mathrm{Sm}^{3+}(1.079 \AA)$ doped for $\mathrm{Bi}^{3+}(1.17 \AA)$ and $\mathrm{V}^{5+}(0.55 \AA)$ for $\mathrm{Ti}^{4+}(0.605 \AA)$. The changes in unit cell dimensions in this study are similar to $\mathrm{La}^{3+}, \mathrm{Pr}^{3+}$, $\mathrm{Nd}^{3+}$ doped BTO. ${ }^{37}$ Structural changes of SBVT can be ascertained from the structural distortion parameters ${ }^{38}$ such as orthorhombicity $[2(a-b) /(a+b)]$, tetragonal strain $(c / a)$ and orthorhombic distortion $(b / a)$ which are calculated to be 0.0032 (0.0066), 6.061 (6.0323) and 0.9967 (0.9934) respectively for SBVT(BTO). From these parameters, it can be seen that the addition of $\mathrm{Sm}$ and $\mathrm{V}$ has the effect of increased tetragonal strain and reduced orthorhombicity. As it is seen in Table 3, the $\left(\mathrm{Ti}_{6} \mathrm{O}_{\text {) octahedral site is more distorted than the }(\mathrm{Ti2O}}\right)$, in terms of $D, \mathrm{QE}$, and BAV. This result is also visually depicted by the 3D rendering of SBVT in Fig. 2(a)-(c). Table 3 also reports the A-O bond length distances and $\mathrm{B}-\mathrm{O}-\mathrm{B}$ bond angles. It is clear that the average $\mathrm{Bi1}-\mathrm{O}$ and $\mathrm{Bi} 2-\mathrm{O}$ distances 2.555(3) and 2.411(1) A respectively, are shorter compared to that of BTO $(2.749 \AA$ and $2.682 \AA) .{ }^{32}$ These results indicate that the $\mathrm{BO}_{6}$ octahedra are relaxed after doping with $\mathrm{Sm}^{3+}$ and $\mathrm{V}^{5+}$.

To track structural changes of SBVT with temperature we performed HTXRD measurements in the range $30-700{ }^{\circ} \mathrm{C}$ and the results are presented in Fig. 3(a)-(d). We observed a shift of characteristic (117) peak towards lower $2 \theta$ positions indicating the unit cell expansion with temperature (inset of Fig. 3(a)). With the increase in temperature the lattice reflections (020) and (200) become resolved around $475{ }^{\circ} \mathrm{C}$ and more distinguishable with further raise in temperature. The full width at

Table 1 Unit cell parameters, unit cell volume, and Rietveld agreement factors for the SBVT specimen ${ }^{a}$

\begin{tabular}{ll}
\hline Crystallographic system & Orthorhombic \\
\hline Space group & $B 2 c b$ \\
$a(\AA)$ & $5.4149(2)$ \\
$b(\AA)$ & $5.3974(2)$ \\
$c(\AA)$ & $32.8194(7)$ \\
Unit cell volume $\left(\AA^{3}\right)$ & $959.19(4)$ \\
No. of reflections & 687 \\
No. of variables & 17 \\
$\chi^{2} ; R_{\mathrm{F} 2} ; R_{\mathrm{wp}}$ & $4.94 ; 8.14 \% ; 6.46 \%$ \\
${ }^{a}$ Lattice parameters of BTO were & \\
${ }^{3} 2.8425(6) \AA$ and $V=967.1 \AA^{3}$. &
\end{tabular}

Table 2 Atomic coordinates occupancies and isotropic displacement parameters $\left(U_{\text {iso }}\right)$ for SBVT

\begin{tabular}{llllll}
\hline Atom & $x$ & $y$ & $z$ & $U_{\text {(iso) }}{ }^{a} \AA^{2}$ & Occupancy \\
\hline $\operatorname{Bi}(1)$ & $0.024(3)$ & $0.995(2)$ & $0.066(4)$ & $2.97(4)$ & $0.68(1)$ \\
$\mathrm{Bi}(2)$ & $0.021(1)$ & $0.012(2)$ & $0.212(2)$ & $1.32(3)$ & $0.82(1)$ \\
$\mathrm{Sm}(1)$ & $0.024(3)$ & $0.995(2)$ & $0.066(4)$ & $2.97(5)$ & $0.32(1)$ \\
$\mathrm{Sm}(2)$ & $0.021(1)$ & $0.012(2)$ & $0.212(2)$ & $1.32(2)$ & $0.18(1)$ \\
$\mathrm{Ti}(1)$ & $-0.013(1)$ & 0 & $1 / 2$ & $0.20(1)$ & $1^{b}$ \\
$\mathrm{Ti}(2)$ & $0.005(1)$ & $0.002(1)$ & $0.373(1)$ & $0.36(1)$ & $1^{b}$ \\
$\mathrm{O}(1)$ & $0.322(3)$ & $0.265(2)$ & $0.007(2)$ & $7.27(2)$ & 1 \\
$\mathrm{O}(2)$ & $0.265(3)$ & $0.263(1)$ & $0.249(1)$ & $0.70(1)$ & 1 \\
$\mathrm{O}(3)$ & $0.086(4)$ & $0.064(3)$ & $0.441(1)$ & $0.98(1)$ & 1 \\
$\mathrm{O}(4)$ & $0.052(3)$ & $0.945(2)$ & $0.319(1)$ & $3.51(8)$ & 1 \\
$\mathrm{O}(5)$ & $0.284(4)$ & $0.253(2)$ & $0.111(1)$ & $0.47(7)$ & 1 \\
$\mathrm{O}(6)$ & $0.217(3)$ & $0.210(3)$ & $0.856(1)$ & $0.73(2)$ & 1
\end{tabular}

${ }^{a}$ Given as $100 \times U_{\text {iso }}{ }^{b}$ To be intended as the sum of Ti plus $\mathrm{V}$.

half maximum (FWHM) of (020)/(200), obtained with pseudo Voigt fittings and plotted against the temperature shows a gradual reduction with the temperature, more rapidly in the range $450-550^{\circ} \mathrm{C}$, indicates the orthorhombic-tetragonal $(\mathrm{O}-\mathrm{T})$ phase transition (Fig. 3(c)). Meanwhile, the reflections (220) and (1115) merge to a single peak with the increase in temperature (Fig. 3(b)). As compared to (220), the (1115) reflection shifts towards lower angle side more significantly and merges with (220) above $475{ }^{\circ} \mathrm{C}$. It is known in BTO that the $c$-axis thermal expansion is larger than that of $a$-and $b$-axes. ${ }^{39}$ Hence the lattice reflections of $c$-axis shift substantially such that the (1115) and (220) merge to a single peak. The lattice parameters $a, b$ and $c$ of the orthorhombic structure increase linearly due to thermal expansion on heating while the $b$-axis exhibits a significant decrease around $475{ }^{\circ} \mathrm{C}$ and then approaches the $a$-axis of the tetragonal structure. This temperature can be considered as the Curie temperature $\left(T_{\mathrm{C}}\right)$ which is $\sim 675{ }^{\circ} \mathrm{C}$ for BTO. As shown in Fig. 3(d), $a$ - and $c$-axis show an increasing trend with temperature with no inflexion in the $T_{\mathrm{C}}$ region. The orthorhombicity decreases with temperature and exhibits a slope change around $T_{\mathrm{C}}$. We did not achieve the equality $a=b$ above $475^{\circ} \mathrm{C}$ and no appearance or disappearance of XRD lines, indicating that the structure achieves a pseudo-tetragonal structure with the validity $a_{0} \approx b_{0} \approx \sqrt{ } 2 a_{\mathrm{T}}$ similar to that observed in BTO by Hirata and Yokokawa. ${ }^{39}$

Raman scattering is a sensitive technique to study lattice vibrational changes and site occupancies of doped ions. Orthorhombic BTO exhibits 24 Raman active modes: $\left(6 \mathrm{~A}_{\mathrm{g}}+2 \mathrm{~B}_{1 \mathrm{~g}}\right.$ $\left.+8 \mathrm{~B}_{2 \mathrm{~g}}+8 \mathrm{~B}_{3 \mathrm{~g}}\right)^{40-42}$ around $32,57,65,90,119,148,189,228,276$, $332,355,449,535,562,614$ and $850 \mathrm{~cm}^{-1}$. However, as shown in Fig. 4(a) only 12 Raman modes are observed at room temperature, around 61, 91, 121, 156, 184, 250, 270, 335, 477, 511, 558, 628 and $851 \mathrm{~cm}^{-1}$, which is partially due to the possible overlap of the same symmetry vibrations or the weak features of some Raman modes. The high frequency peaks in the range $200-850$ $\mathrm{cm}^{-1}$ originate from the internal vibrational modes of $\mathrm{TiO}_{6}$ octahedra, due to the large intragroup binding energy in the octahedra as well as lighter $\mathrm{Ti}^{4+}$ ions. The Raman modes at 270 , $335,558,620,851 \mathrm{~cm}^{-1}$ can be assigned to the $A_{1 g}$ character, 
Table 3 Bond length distances $(\AA)$, average length distances $(\AA)$, distortion index $(D)$, quadratic elongation $(Q E)$, bond angle variance $\left(\mathrm{BAV}, \operatorname{deg}^{2}\right)$, and selected angles $\left({ }^{\circ}\right)$, for the $\mathrm{TiO}_{6}$ octahedral sites in SBVT

\begin{tabular}{ll}
\hline Ti1 & Distance \\
\hline $\mathrm{Ti}(1)-\mathrm{O}(1) \times 2$ & $2.22677(5)$ \\
$\mathrm{Ti}(1)-\mathrm{O}(1) \times 2$ & $1.70044(4)$ \\
$\mathrm{Ti}(1)-\mathrm{O}(3) \times 2$ & $2.05170(4)$ \\
Distortion index $(D)$ & 0.0979 \\
Quadratic elongation $(\mathrm{QE})$ & 1.0649 \\
Bond angle variance $\left(\mathrm{BAV}, \mathrm{deg}^{2}\right)$ & 180.06 \\
$\langle\mathrm{Ti}(1)-\mathrm{O}\rangle$ & $1.9929(1)$ \\
\hline $\mathrm{Ti} 2$ & Distance \\
\hline $\mathrm{Ti}(2)-\mathrm{O}(3)$ & \\
$\mathrm{Ti}(2)-\mathrm{O}(4)$ & $2.28921(4)$ \\
$\mathrm{Ti}(2)-\mathrm{O}(5)$ & $1.80452(3)$ \\
$\mathrm{Ti}(2)-\mathrm{O}(5)$ & $2.09354(4)$ \\
$\mathrm{Ti}(2)-\mathrm{O}(6)$ & $1.89963(4)$ \\
$\mathrm{Ti}(2)-\mathrm{O}(6)$ & $1.97343(4)$ \\
Distortion index $(D)$ & $1.89270(4)$ \\
Quadratic elongation $(\mathrm{QE})$ & 0.0667 \\
Bond angle variance $\left(\mathrm{BAV}, \mathrm{deg}^{2}\right)$ & 1.0370 \\
$\langle\mathrm{Ti}(2)-\mathrm{O}\rangle$ & 99.94 \\
\hline
\end{tabular}

Bi1 Distance

$\operatorname{Bi}(1)-O(1)$

$\mathrm{Bi}(1)-\mathrm{O}(1)$

$\mathrm{Bi}(1)-\mathrm{O}(1)$

$\mathrm{Bi}(1)-\mathrm{O}(3)$

$\mathrm{Bi}(1)-\mathrm{O}(3)$

$\mathrm{Bi}(1)-\mathrm{O}(5)$

$\mathrm{Bi}(1)-\mathrm{O}(5)$

$\mathrm{Bi}(1)-\mathrm{O}(6)$

$\langle\mathrm{Bi}(1)-\mathrm{O}\rangle$

Bi2

$\mathrm{Bi}(2)-\mathrm{O}(2)$

$\mathrm{Bi}(2)-\mathrm{O}(2)$

$\mathrm{Bi}(2)-\mathrm{O}(2)$

$\mathrm{Bi}(2)-\mathrm{O}(2)$

$\mathrm{Bi}(2)-\mathrm{O}(4)$

$\mathrm{Bi}(2)-\mathrm{O}(4)$

$\langle\mathrm{Bi}(2)-\mathrm{O}\rangle$

Bond

$\mathrm{Ti}(1)-\mathrm{O}(1)-\mathrm{Ti}(1)$

$\mathrm{Ti}(1)-\mathrm{O}(3)-\mathrm{Ti}(2)$

$\mathrm{Ti}(2)-\mathrm{O}(5)-\mathrm{Ti}(2)$

$\mathrm{Ti}(2)-\mathrm{O}(6)-\mathrm{Ti}(2)$

Ti(1)-O(1)-Ti(1)

$2.91294(4)$

$2.57267(4)$

2.90733(4)

2.36255(7)

2.40035(7)

$2.46972(4)$

2.38814(4)

$2.429(26)$

2.555(3)

Distance

2.25125(4)

2.29677(4)

2.41572(4)

$2.20710(3)$

2.55551(6)

$2.74120(7)$

2.411(1)

Angle $\left({ }^{\circ}\right)$

153.3(1)

147.9(1)

148.2(1)

159.6(2)

153.3(1)

and the one at $477 \mathrm{~cm}^{-1}$ is related to $\mathrm{B}_{1 \mathrm{~g}}$ character. ${ }^{40}$ The peaks below $200 \mathrm{~cm}^{-1}$ are ascribed to two different $\mathrm{Bi}$ sites, the $\mathrm{Bi}_{2} \mathrm{O}_{2}$ layer and perovskite units. The mode at $65 \mathrm{~cm}^{-1}$ is assigned as a rigid-layer mode, which originates from $\mathrm{Bi}$ displacement in the $\mathrm{Bi}_{2} \mathrm{O}_{2}$ layers. The three modes of SBVT at 91, 121 and 156 $\mathrm{cm}^{-1}$, related to the $\mathrm{Bi}$ atoms in the perovskite units, have become diffused. The mode at $65 \mathrm{~cm}^{-1}$ of BTO is moved to

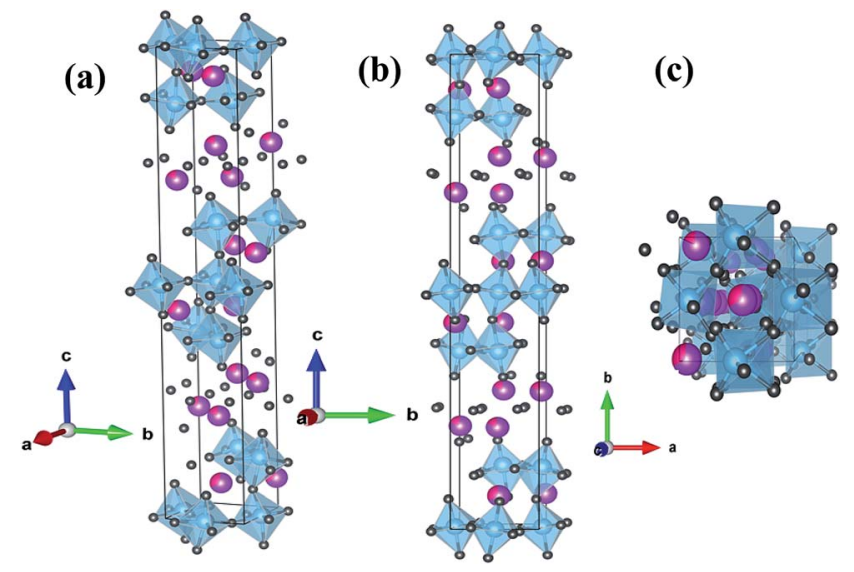

Fig. 2 (a) 3D rendering of SBVT, in the ball-and-stick and polyhedron models, obtained using the structural data extracted from GSAS. (b) Along the a-axis direction; (c) along the $c$-axis direction. In the 3D renderings, the small dark grey spheres represent oxygen, the bigger light-blue sphere titanium, whilst the bigger violet spheres bismuth (in it is shown the fraction of samarium, magenta color).

lower frequency of $61 \mathrm{~cm}^{-1}$ due to structural hardening due to doping. This peak broadening was caused by the compositional inhomogeneity of the $\mathrm{Bi}$ atoms in the perovskite units. The blue shift observed in these modes is justified as Bi atoms are 1.39 times heavier than of Sm. The diffused low frequency modes in rare-earth doped BTO is reported to arise from the partial substitution of these atoms into $\left(\mathrm{Bi}_{2} \mathrm{O}_{2}\right)^{2+}$ layers resulting in cation disorder in the $\left(\mathrm{Bi}_{2} \mathrm{O}_{2}\right)^{2+}$ layers. ${ }^{43}$ However, in SBVT, based on the structural refinement results, it is clear that $\mathrm{Sm}$ is doped only at the $\mathrm{Bi}$ atomic sites of the $\left(\mathrm{Bi}_{2} \mathrm{Ti}_{3} \mathrm{O}_{10}\right)$ units. Raman modes at $228,332,535,614,850 \mathrm{~cm}^{-1}$ of BTO were moved to high frequency side with doping, which is due to the simultaneous doping of lighter Sm and $\mathrm{V}$ atoms for $\mathrm{Bi}$ and $\mathrm{Ti}$ at $\mathrm{A}-$ and B-sites of the lattice respectively. The modes at 270 and 330 $\mathrm{cm}^{-1}$ correspond to the torsional bending of $\mathrm{TiO}_{6}$ octahedra and the modes at 558 and $851 \mathrm{~cm}^{-1}$ are related to the stretching of O-Ti octahedral chains between $\left(\mathrm{Bi}_{2} \mathrm{O}_{2}\right)^{2+}$ layers. The Raman mode at $558 \mathrm{~cm}^{-1}$ is due to the combination of stretching and bending of the oxygen octahedra. From the results of Table 3 it is clear that the average Ti-O distance of SBVT is shorter and the octahedral tilting is reduced compared to BTO. ${ }^{32,44}$ The relaxation in structural distortions can also be seen from the orthorhombicity, which is $3.24 \times 10^{-3}$ and $7.24 \times 10^{-3}$ for SBVT and BTO respectively. These results match well with the significant shifting of Raman modes corresponding to octahedral tilting.

We measured temperature dependent Raman spectra in order to understand the effect of Sm and V doping on the phase transition behavior of BTO in the temperature range $22-600{ }^{\circ} \mathrm{C}$ and the results are shown in Fig. 4(b) and (c). The Raman modes around 61, 91 and $270 \mathrm{~cm}^{-1}$ exhibited a significant red shift as well as the weakening (large FWHM) with the increase in temperature. At the same time the room temperature modes at 121, 188, 335 and $628 \mathrm{~cm}^{-1}$ show a gradual weakening with temperature and disappear in the background above $450{ }^{\circ} \mathrm{C}$. The intensity of high frequency modes shows a gradual 

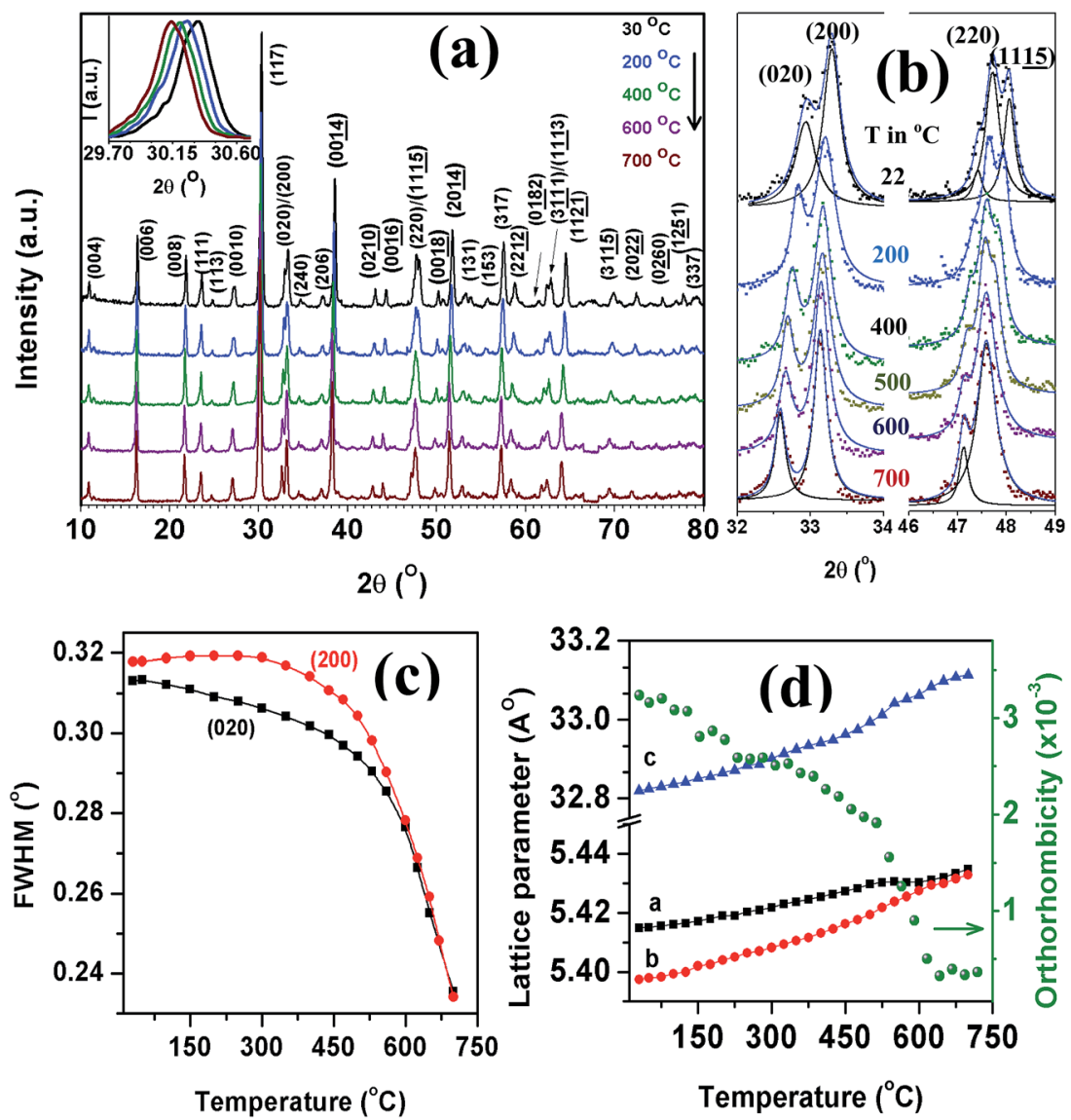

Fig. 3 (a) HTXRD $\theta-2 \theta$ scans of SBVT sample measured in the $2 \theta$ range of $10-80^{\circ}$. Temperature dependent changes in the profiles of $(020) /(200)$ and (220)/(1115) reflections (b), FWHM of $(020) /(200)$ peaks (c) and unit cell parameters (d). Arrow in (d) indicates the phase transition temperature.

decrease with the increase in temperature, which can be attributed to the decrease of optical penetration depth due to the increase of conductivity as well as the decrease in the deformation of $\mathrm{TiO}_{6}$ octahedra in the region of structural phase transition. ${ }^{45}$ From the HTXRD studies (Fig. 3(d)) the O-T transition is expected around $475{ }^{\circ} \mathrm{C}$ and the mode weakening/ disappearance observed in Fig. 4 corroborates the phase transition. These effects at high temperature can be ascribed to the anharmonic phonon-phonon interactions of the lattice leading to thermal disorder. ${ }^{45}$ With the increase in temperature, there will be a change in bond length between oxygen and cations which is also responsible for the shifting of peak positions.

The phase transition of BTO is known to be around $675{ }^{\circ} \mathrm{C}$ and the drop in $T_{\mathrm{C}}$ for SBVT can be understood by the following: the soft mode of BTO (around the wavenumber $30 \mathrm{~cm}^{-1}$ ) is determined by the difference between the short-range repulsive force and the coulombic force. The vanishing of the soft mode around $\mathrm{O}-\mathrm{T}$ transition is the result of the balance between these two forces. The replacement of smaller $\mathrm{Sm}^{3+}$ for $\mathrm{Bi}^{3+}$ is expected to change the short-range force constant that may suppress the orthorhombic distortion and lower the phase transition temperature. The ferroelectricity of BTO-based materials is related to the displacement of $\mathrm{Bi}$ atoms along the $a$-axis with respect to the $\mathrm{TiO}_{6}$ octahedra. ${ }^{46}$ From Fig. 4(b) and (c) it is noteworthy that the modes corresponding to Bi atomic vibrations experience the phase transition earlier than those of octahedra as the bending of octahedra can be disturbed by the vibrations of $\mathrm{Bi}$ atoms in perovskite slabs.

The microstructure and crystallinity of SBVT samples were studied by electron microscopy. Fig. 5 shows the SEM micrograph of platelet-like crystals typical for Aurivillius - type structure, caused by the anisotropic structure. No secondary phases were detected, which is consistent with the XRD results. The samples are uniform and dense with randomly oriented platelets with an average size of $5 \mu \mathrm{m}$ long and $0.9 \mu \mathrm{m}$ thick. From the SEM cross-section we can conclude that the porosity is mainly located at grain boundaries. It has to be noted that an elongated morphology is reported to be favorable for photocatalytic applications. ${ }^{47}$ More detailed crystallographic studies were made by TEM. Fig. 6(a) shows a cross-sectional highresolution transmission electron microscope (HRTEM) image of SBVT along the [110] zone-axis. The periodic fringes corresponding to the $\left(\mathrm{Bi}_{2} \mathrm{O}_{2}\right)^{2+}$ layers are clearly observed, with a spacing of about $1.7 \mathrm{~nm}$, approximated to $c / 2$. The Fig. 6(b) shows the marked region that reveals the microstructure with fluorite-like $\left(\mathrm{Bi}_{2} \mathrm{O}_{2}\right)^{2+}$ layers imaged as heavy lines interleaved by three perovskite-type layers. The SAED pattern in Fig. 6(c) further indicates the modulation of perovskite and $\left(\mathrm{Bi}_{2} \mathrm{O}_{2}\right)^{2+}$ 

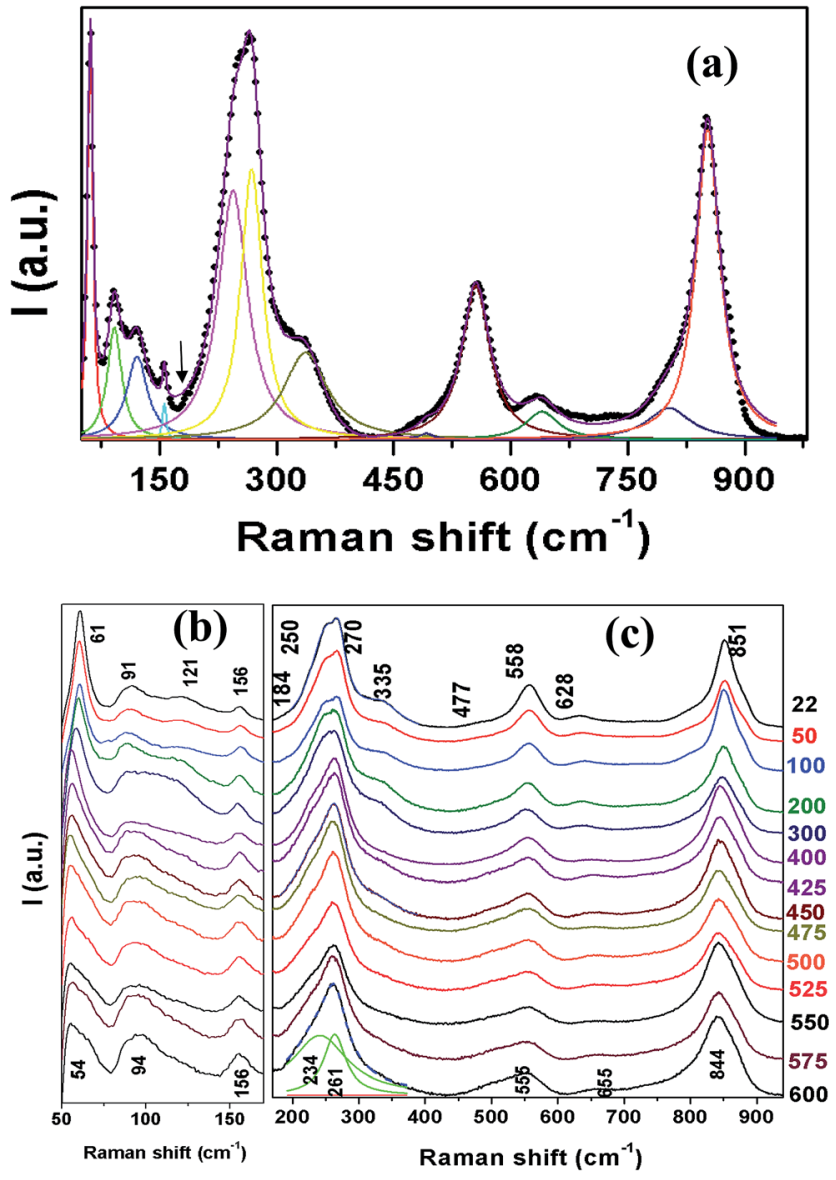

Fig. 4 (a) Normalized Raman spectra of SBVT measured at room temperature. Temperature evolution of Raman spectra obtained in the frequency range $50-170 \mathrm{~cm}^{-1}$ (b) and $170-940 \mathrm{~cm}^{-1}$ (c).

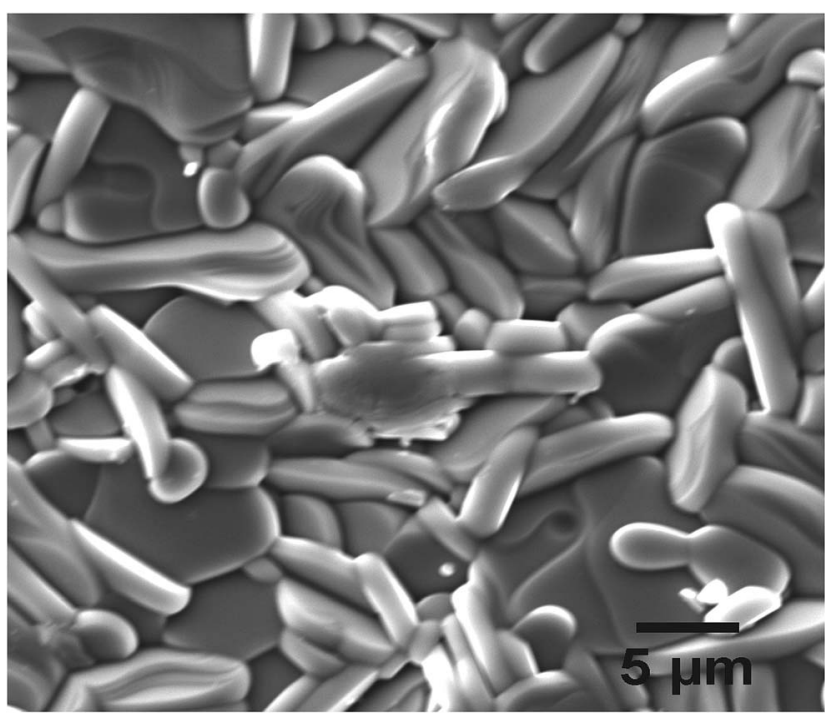

Fig. 5 SEM micrograph of SBVT surface. Typical plate-like structure of the Aurivillius phase is visible on the edge of the crystallites as a set of lamellas.

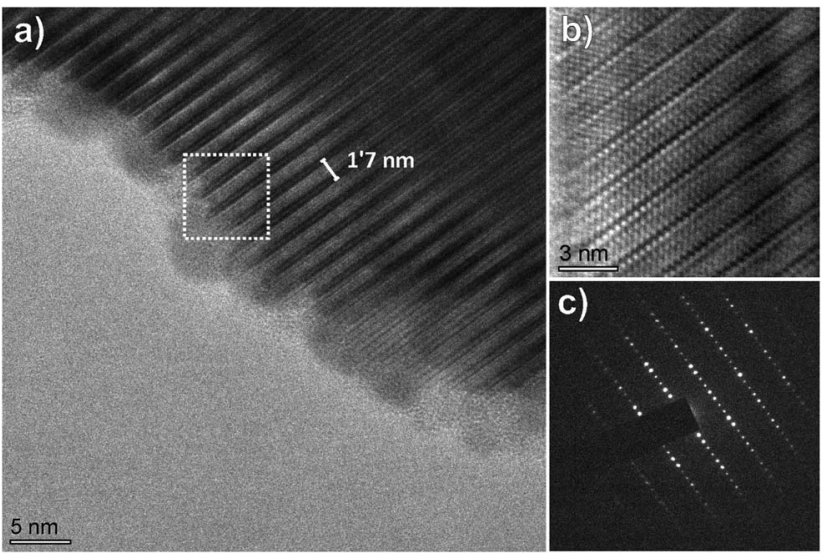

Fig. 6 (a) TEM micrograph of SBVT sample along [110] zone axis, showing periodic alternations along $c$-axis. (b) HRTEM micrograph showing alteration of fluorite-type $\mathrm{Bi}$-rich segments and intermediate perovskite layers; the image was ABS-filtered. (c) SAED pattern, according to single-crystal diffraction pattern showing extra reflection at $1 / 4$ of the spacing of the prototype unit cell. Thus the periodicity of the modulation is 1-3-1, corresponding to 1 darker Bi-rich band, followed by 3 perovskite layers.

layers. These features clearly confirm the $n=3$ structure of highly crystalline Aurivillius SBVT phase with no intergrowths caused by phase separation. Fig. 7(a) shows a HRTEM image of SBVT in [001] orientation parallel to the electron beam. The coherently spaced lattice fringes can be seen from the high magnification HRTEM image (Fig. 7(b)). The corresponding selected-area electron diffraction (SAED) pattern in Fig. 7(c) shows a near four-fold symmetry as the lattice parameters $a$ and

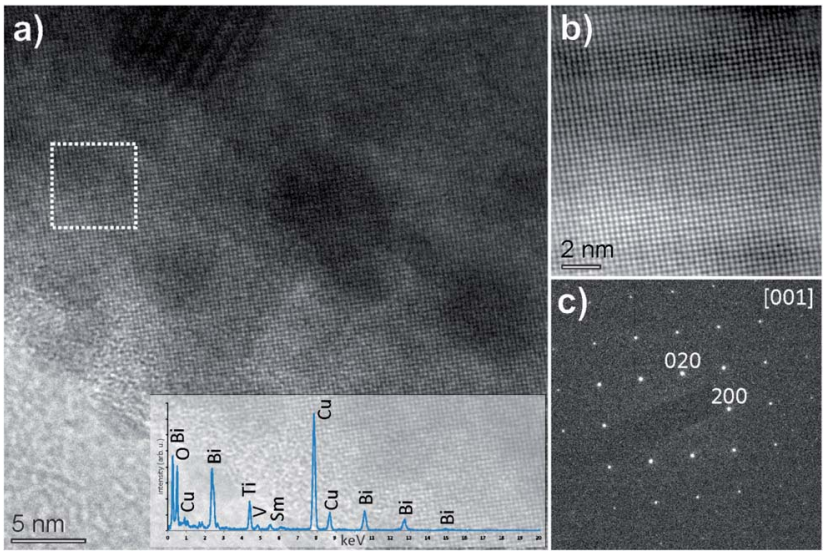

Fig. 7 (a) HRTEM micrograph of SBVT in [001] parallel to the electron beam. Darker regions correspond to Bi exsolutions, which begin to grow only after seconds of exposure to the electron beam. The inset is EDS spectra recorded on the same region, conforming $\mathrm{Sm}, \mathrm{Bi}, \mathrm{Ti}, \mathrm{V}$ and O composition, while Cu peak is an artefact from the Cu support grid. (b) ABSF filtered HRTEM micrograph of SBVT showing the coherent crystalline structure along $a$ and $b$ directions, without any periodic exsolutions. The corresponding SAED pattern (c) shows near four fold symmetry; lattice parameters $a$ and $b$ being identical. The reflections marked as 020 and 200 correspond to $d$-values of approx. $5.55 \AA$, which is a good agreement with the values of 5.4149 and $5.3974 \AA$, obtained from XRD. 
$b$ are similar. The most intense spots in the pattern could be indexed to the room temperature orthorhombic cell with $a$ and $b$ parameters estimated to be $\sim 5.55 \AA$, which is in good agreement with XRD data. The chemical composition of SBVT studied by TEM-EDS (inset of Fig. 7(a)) reveals the presence of $\mathrm{Sm}, \mathrm{Bi}, \mathrm{Ti}, \mathrm{V}$ and $\mathrm{O}$ atoms. From the atomic percentages we can confirm that the calculated cationic ratios match well with the expected ones.

Dielectric measurements were carried out in the temperature range $30-600{ }^{\circ} \mathrm{C}$ and the results are presented in Fig. $\mathrm{S} 2 . \dagger$ With the increase in temperature dielectric constant $\left(\varepsilon_{\mathrm{r}}^{\prime}\right)$ and the loss $(\tan \delta)$ values increased steeply due to the increase in space charge polarization at lower frequencies. A clear $T_{\mathrm{C}}$ can be seen from the $\varepsilon^{\prime}{ }_{\mathrm{r}}$ measured at frequencies $\geq 100 \mathrm{kHz}$; at $100 \mathrm{kHz} \varepsilon_{\mathrm{r}}^{\prime}$ is 130, $\tan \delta \sim 0.003$ and $T_{\mathrm{C}}=495{ }^{\circ} \mathrm{C}$ (Fig. S2a $\dagger$ ). The tan $\delta$ also exhibits inflexion point at this temperature (Fig. S2 b $\dagger$ ), obeying the results of HTXRD and Raman studies. The onset of decay in FWHM vs. temperature curve of $(200) /(020)$ XRD peak (Fig. 3(c)), observed around $490{ }^{\circ} \mathrm{C}$, is thus related to $T_{\mathrm{C}}$.

The room temperature ferroelectric properties are depicted in Fig. 8. SBVT ceramic exhibited well-saturated $P-E$ hysteresis loops without dielectric breakdown. The remanent polarization $\left(2 P_{\mathrm{r}}\right)$ and coercive field $\left(2 E_{\mathrm{C}}\right)$ were $40.66 \mu \mathrm{C} \mathrm{cm}^{-2}$ and $145 \mathrm{kV}$ $\mathrm{cm}^{-1}$, respectively. The saturation properties were characterized by the evolution of $P_{\mathrm{r}}, P_{\max }\left(P_{\mathrm{S}}\right)$ and $E_{\mathrm{C}}$ as a function of applied field (Fig. 8(c)). The $P_{\mathrm{r}}$ and polarization $P_{\mathrm{S}}$ shows a pronounced increase with the applied field, while a gradual increase was seen in the region of $E \approx 2 E_{\mathrm{C}}$. The polarization current (Fig. 8(b)) reaches a maximum value at the drive field of about $E_{\mathrm{C}}$ (Fig. 8(c)) indicating the switching of ferroelectric domains. The $P_{\mathrm{r}}\left(\& E_{\mathrm{C}}\right)$ values obtained in this study are comparable to
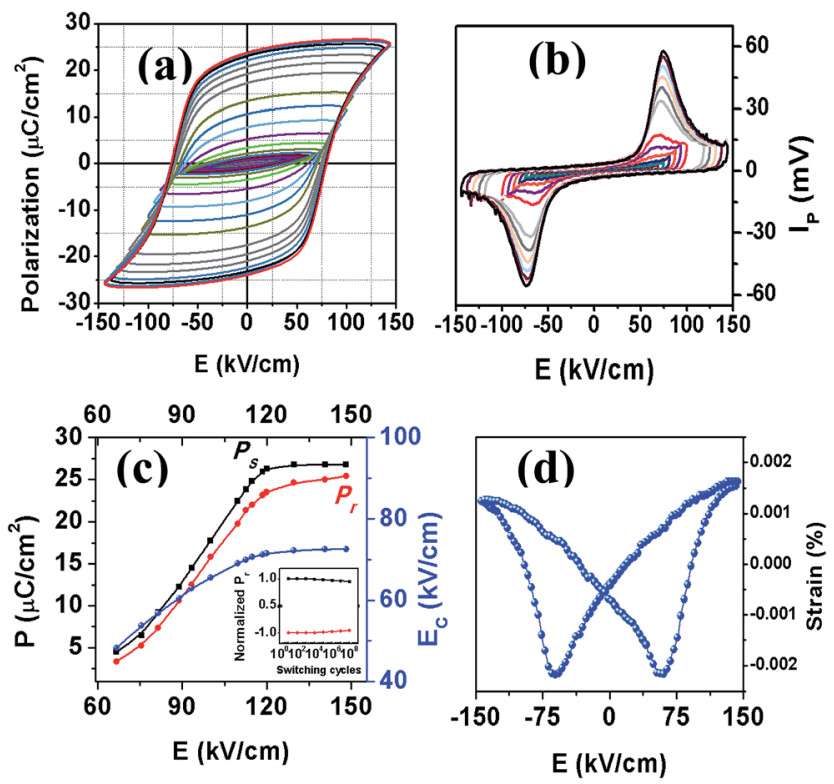

Fig. 8 Room temperature polarization-electric field hysteresis loops of SBVT. Inset: electric field dependence of polarization current. (b) $P_{r}$ vs. electric field. (c) Room temperature piezoelectric strain loop of SBVT at $1 \mathrm{~Hz}$. Inset of (c): normalized $P_{\mathrm{r}}$ as a function of switching cycles. Comparison of $P-E$ loops before and after $10^{8}$ cycles is presented in fig. S4. $\uparrow$ (d) Piezoelectric strain vs. electric field. recent literature on rare-earth doped BTO: $23.9\left(125 \mathrm{kV} \mathrm{cm}^{-1}\right)$ and $32.6 \mu \mathrm{C} \mathrm{cm}^{-2}\left(120 \mathrm{kV} \mathrm{cm}^{-1}\right)$ for $\mathrm{La}$ and $\mathrm{Nd}$ doped BTO respectively, ${ }^{48} 35 \mu \mathrm{C} \mathrm{cm}{ }^{-2}\left(148 \mathrm{kV} \mathrm{cm}{ }^{-1}\right)$ for $\mathrm{Bi}_{3.25} \operatorname{Pr}_{0.75} \mathrm{Ti}_{2.97^{-}}$ $\mathrm{V}_{0.03} \mathrm{O}_{12}$ ceramics, ${ }^{37} 30.4 \mu \mathrm{C} \mathrm{cm}{ }^{-2}\left(130 \mathrm{kV} \mathrm{cm}^{-1}\right)$ for $\mathrm{Bi}_{3.25^{-}}$ $\mathrm{La}_{0.75} \mathrm{Ti}_{2.97} \mathrm{~V}_{0.03} \mathrm{O}_{12}$ ceramics, ${ }^{49} 26 \mu \mathrm{C} \mathrm{cm}^{-2}\left(108 \mathrm{kV} \mathrm{cm}{ }^{-1}\right)$ for $\mathrm{Bi}_{3.15} \mathrm{Nd}_{0.85} \mathrm{Ti}_{2.97} \mathrm{~V}_{0.03} \mathrm{O}_{12}$ (ref. 50) and $25 \mu \mathrm{C} \mathrm{cm}^{-2}\left(125 \mathrm{kV} \mathrm{cm}^{-1}\right)$ for $\mathrm{Bi}_{3.25} \mathrm{Sm}_{0.75} \mathrm{Ti}_{2.97} \mathrm{~V}_{0.03} \mathrm{O}_{12}$ ceramics. ${ }^{51}$ In BTO, the doping of rare-earth elements is supposed to reduce the oxygen vacancies and improve polarization and ferroelectric fatigue resistance. The enhanced polarization of SBVT compared to other rare-earth doped BTO is due to the smaller ionic size of Sm, resulting in larger structural distortion. The SBVT ceramic has larger BAV and tetragonal strain compared to BTO. At the same time the presence of higher valence $\mathrm{V}^{5+}$ for $\mathrm{Ti}^{4+}$ is effective to suppress the oxygen vacancies/vacancy complexes accumulated near domain boundaries resulting in domain pinning and reduced $P_{\mathrm{r}}{ }^{7,8}$

The piezoelectric strain measured for SBVT is shown in Fig. 8(d). The $S-E$ loop of SBVT ceramic shows a typical butterfly shaped loop for ferroelectrics. The $S_{33} \max$ observed at the maximum electric field, $\sim 0.02 \times 10^{-3}$, is comparable to the same observed for spark plasma sintered $\mathrm{Bi}_{3.15} \mathrm{Nd}_{0.85} \mathrm{Ti}_{3} \mathrm{O}_{12}$ ceramics. ${ }^{52}$ The Aurivillius materials have lower piezoelectric strain compared to conventional ferroelectrics such as $\mathrm{Pb}(\mathrm{Zr}, \mathrm{Ti})$ $\mathrm{O}_{3}$ due to the two-dimensional orientation restrictions by rigid $\left(\mathrm{Bi}_{2} \mathrm{O}_{2}\right)$ layers. The piezoelectric strain changes in this class of materials are related empirically to structural distortion by a factor $(a-b) / b(\%)$, which is related to the presence of non$180^{\circ}$ domains which appear when they are cooled through the $T_{\mathrm{C}}$ in order to minimize electrical and mechanical internal energy. Based on the unit cell parameters of other rare-earth (La, Nd, Pr) doped ${ }^{37,42,48,50}$ and V-doped $\mathrm{BTO}^{7}$ we found that the structural distortion of SBVT $(0.32 \%)$ is stronger. The internal stresses are expected to be higher in the lattice with small structural distortion which is not reduced fully by the formation of non- $180^{\circ}$ domains.

We measured XPS spectra in order to see the defect states of different ions of SBVT composition. Fig. 9(a)-(d) and S3(a)-(c) $\dagger$ shows the high resolution XPS spectra obtained for Ti 2p, Bi $4 \mathrm{f}$, Sm 3d, V 2p and O 1s core-levels. The BE and FWHM of the Bi $4 f_{7 / 2}$, Ti $2 p_{3 / 2}, V 2 p_{3 / 2}$, Sm $3 d_{5 / 2}$ and $O$ 1s peaks for the SBVT sample are summarized in Table 4 . The BE of the sharp peak in the fitted $\mathrm{Ti} 2 \mathrm{p}$ spectra (Fig. 9(b)), at $458.4 \mathrm{eV}$, is typically assigned in the literature to $\mathrm{Ti} 2 \mathrm{p}_{3 / 2}$ in $\mathrm{TiO}_{2}$ chemical environment. ${ }^{53,54}$ The sharpness and symmetrical shape of this peak indicates the presence of titanium in only one oxidation state, $\mathrm{Ti}^{4+}$. Moreover, three extra components were fitted in the titanium region, in order of increasing BE: Ti $2 \mathrm{p}_{1 / 2}$, at $5.7 \mathrm{eV}$ from Ti $2 \mathrm{p}_{3 / 2}$, Bi $4 \mathrm{~d}_{3 / 2}$ and a Ti $2 \mathrm{p}$ satellite peak. The Bi $4 \mathrm{f}$ spectrum (Fig. 9(a)) shows two well separated symmetric peaks, corresponding to $\mathrm{Bi} 4 \mathrm{f}_{7 / 2}$ and $\mathrm{Bi} 4 \mathrm{f}_{5 / 2}$, with an orbital splitting of $5.3 \mathrm{eV}$. The $\mathrm{Bi} 4 \mathrm{f}_{7 / 2}$ peak appears at a $\mathrm{BE}$ of $159.5 \mathrm{eV}$, in good agreement with the values assigned in the literature to $\mathrm{Bi}^{3+}$ in compounds like $\mathrm{Bi}_{2} \mathrm{O}_{3}$, or $\mathrm{Bi}_{2} \mathrm{Ti}_{2} \mathrm{O}_{7}{ }^{55}$ The presence of $\mathrm{Sm}$ at $\mathrm{A}$ site of perovskite lattice can be confirmed from the $\mathrm{Sm} 3 \mathrm{~d}$ core level XPS spectrum (Fig. 9(c)). The Sm $3 \mathrm{~d}_{5 / 2}$ and $\mathrm{Sm} 3 \mathrm{~d}_{3 / 2}$ levels are observed at binding energies of 1083.3 and $1110.1 \mathrm{eV}$, respectively. The shape of the spectrum and $\mathrm{BE}$ values indicates 

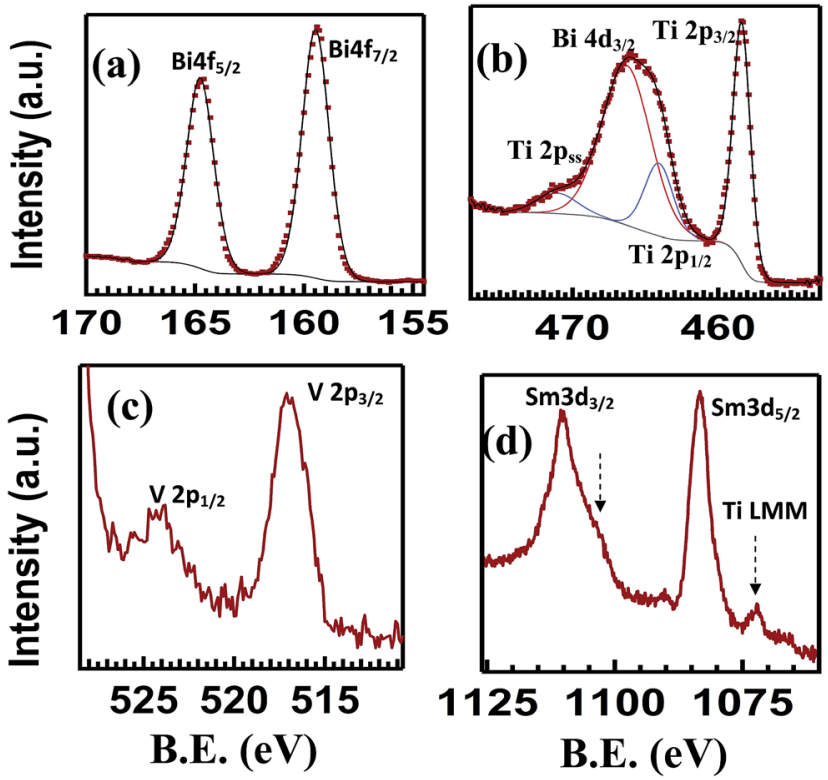

Fig. 9 XPS of SBVT sample: (a) Ti 2p, (b) Bi 4f, (c) Sm 3d and (d) V 2p core-levels.

Table 4 Resume of binding energy and full-wide half-maximum values for the main XPS peaks

\begin{tabular}{lccccr}
\hline & $\mathrm{Ti} 2 \mathrm{p}_{3 / 2}$ & $\mathrm{Bi} 4 \mathrm{f}_{7 / 2}$ & ${\mathrm{Sm} 3 \mathrm{~d}_{5 / 2}}$ & $\mathrm{~V} \mathrm{2 \textrm {p } _ { 3 / 2 }}$ & $\mathrm{O} 1 \mathrm{~s}$ \\
\hline BE $(\mathrm{eV})$ & 458.4 & 159.5 & 1083.3 & 516.9 & 530.1 \\
FWHM $(\mathrm{eV})$ & 1.4 & 1.46 & 3.9 & 2.2 & 1.6
\end{tabular}

a $\mathrm{Sm}_{2} \mathrm{O}_{3}$ chemical environment. ${ }^{56}$ The features targeted in green in the figure point at the contribution to the spectrum from the Ti LMM Auger peak. The V 2p spectrum shows two small peaks corresponding to $\mathrm{V} 2 \mathrm{p}_{3 / 2}$ and $\mathrm{V} 2 \mathrm{p}_{1 / 2}$. Furthermore, the tail of the $\mathrm{O}$ 1s peak appears at higher BE (Fig. $9(\mathrm{~d}))$. The $\mathrm{V} 2 \mathrm{p}_{3 / 2}$ peak can be described as a broad peak centered at $516.9 \mathrm{eV}$. The BE and the broadness of the peak suggests the contribution of mixed oxides of $\mathrm{V}^{4+}$ and $\mathrm{V}^{5+}$. Nevertheless, within our XPS data it is difficult to clearly quantify the ratio between these two components. From these results we confirm that co-doping Sm and $\mathrm{V}$ at A- and B-sites of BTO lattice resulted in the reduction of Bi loss during high temperature ceramic processing as well as oxygen vacancies/its complexes. These factors help to improve ferroelectric polarization and fatigue resistance, ${ }^{7,8}$ revealed in the inset of Fig. 8(c) and $\mathrm{S} 4 \dagger$ where the normalized polarization shows no significant degradation up to $10^{8}$ switching cycles.

In order to observe piezo-response (PR) at the granular scale and observe domain switching of SBVT, we performed PFM measurements. The PR was measured from the mirror polished surface of the sample after thermal etching. Fig. 10(a) shows the topographic image of SBVT which is dominated by parallel grooves resulting from the polishing process. The out-of-plane PR amplitude and phase scans, depicted in Fig. 10(b) and (c) respectively, clearly show domains near $5 \mu \mathrm{m}$ size, attesting genuine PR contrast without any relevant cross talk to topography which has regular grooves and very low rugosity averaging $\sim 1 \mathrm{~nm}$, although it is possible that domain size and walls could be delimited by grain boundaries. Fig. 10(d) and (e) represent the PR amplitude and phase scans respectively, after bias lithography local poling experiments with $\pm 30 V_{\mathrm{dc}}$ (as outlined in Fig. 10(a)). The PR amplitude contrast presented in Fig. 10(d) reveals a significant imprint and domain reversal features with no visible surface damage, although the PR phase visible in Fig. 10(e) does not present such a strong response. The poor piezoresponse in phase in these experiments can be due to the low dielectric constant between the tip and sample surface as observed in our previous work on piezoelectric ceramics..$^{52}$ Local piezoresponse hysteresis loop measured by applying a dc voltage of $\pm 40 \mathrm{~V}$ between PFM tip fixed above the surface and bottom electrode of the sample is shown in Fig. 10(f). The observation of clear hysteresis suggests the switchable piezoresponse at the nanoscale. Clear hysteresis loops observed for different grain positions indicate that there is no significant effect of grain orientation on local polar character. These studies attest the domain switching and ferroelectric character of SBVT ceramic at the nanoscale.

Fig. 11 shows the UV-Vis diffuse reflectance spectra measured on SBVT powders. The electronic transition in the Aurivillius $\mathrm{Bi}_{4} \mathrm{Ti}_{3} \mathrm{O}_{12}$ phase is assumed to be indirect allowed, ${ }^{57}$ thus the apparent optical $E_{g}$ was calculated via the Tauc formalism, that is a plot of $(\alpha h \nu)^{1 / \gamma}$ as a function of the photon energy $(h \nu){ }^{58,59}$ The coefficient $\alpha$ can be derived by the KubelkaMunk theory: ${ }^{60} a \approx \frac{k}{s}=\frac{\left(1-R_{\infty}\right)^{2}}{2 R_{\infty}} \equiv F\left(R_{\infty}\right)$ where $k$ and $s$ are the absorption and scattering coefficients, $\alpha$ is the pseudoabsorption coefficient. As SBVT is an indirect semiconductor material, the coefficient $\gamma$ is equal to 2, thus, the apparent optical $E_{\mathrm{g}}$ of the semiconductor material was obtained from the $x$-axis $(\alpha=0)$ intercept of the line which is tangent to the inflection point of the $(\alpha h \nu)^{1 / 2} v s$. $h v$ curve. This was found by fitting the transformed Kubelka-Munk equation against the photon energy with a sigmoidal Boltzmann function. The apparent optical $E_{\mathrm{g}}$ value was afterward obtained from the $x$-axis intercept of the line tangent to the inflection point of that curve. SBVT spectrum consists of two distinct absorption edges, the first one, at around $400 \mathrm{~nm}$, the other at approximately $600 \mathrm{~nm}$, as shown in the inset of the figure. The absorption edge located at higher energy, corresponding to an apparent $E_{\mathrm{g}}$ of $2.88 \mathrm{eV}$ (431 $\mathrm{nm}$ ), noted here as $E_{\mathrm{g}}^{1}$, is consistent with the $E_{\mathrm{g}}$ for $\mathrm{Bi}_{4} \mathrm{Ti}_{3} \mathrm{O}_{12}$ found by Liu et al. ${ }^{21}$ On the other hand, the $E_{\mathrm{g}}$ found at lower energy, noted here as $E_{g}^{2}$, and estimated to be equal to $2.02 \mathrm{eV}(613 \mathrm{~nm})$, can be due to contributions of samarium and/ or vanadium from the valence band states (hybrid orbitals of $\mathrm{Bi}$ 6s and $\mathrm{O} 2 \mathrm{p}$ ) to the conduction band states of $\mathrm{Ti} 3 \mathrm{~d} .{ }^{61} \mathrm{~A}$ conceivable scheme depicting the electrochemical band edges of SBVT - relative to the normal hydrogen electrode (NHE) at pH $=0-$ can be drawn. The band edge positions of the conduction band (CB) minimum, as well as of the valence band (VB) maximum of a semiconductor material, can be evaluated knowing the absolute electronegativity values of the constituent atoms of the material: ${ }^{62,63} E_{\mathrm{CB}}=\chi_{\mathrm{A}_{a} \mathrm{~B}_{b} \mathrm{C}_{c}}-\frac{1}{2} E_{g}+E_{0}$ and $E_{\mathrm{VB}}=E_{g}$ $+E_{\mathrm{CB}}$. Here $E_{\mathrm{g}}$ is the band gap of the semiconductor material, 

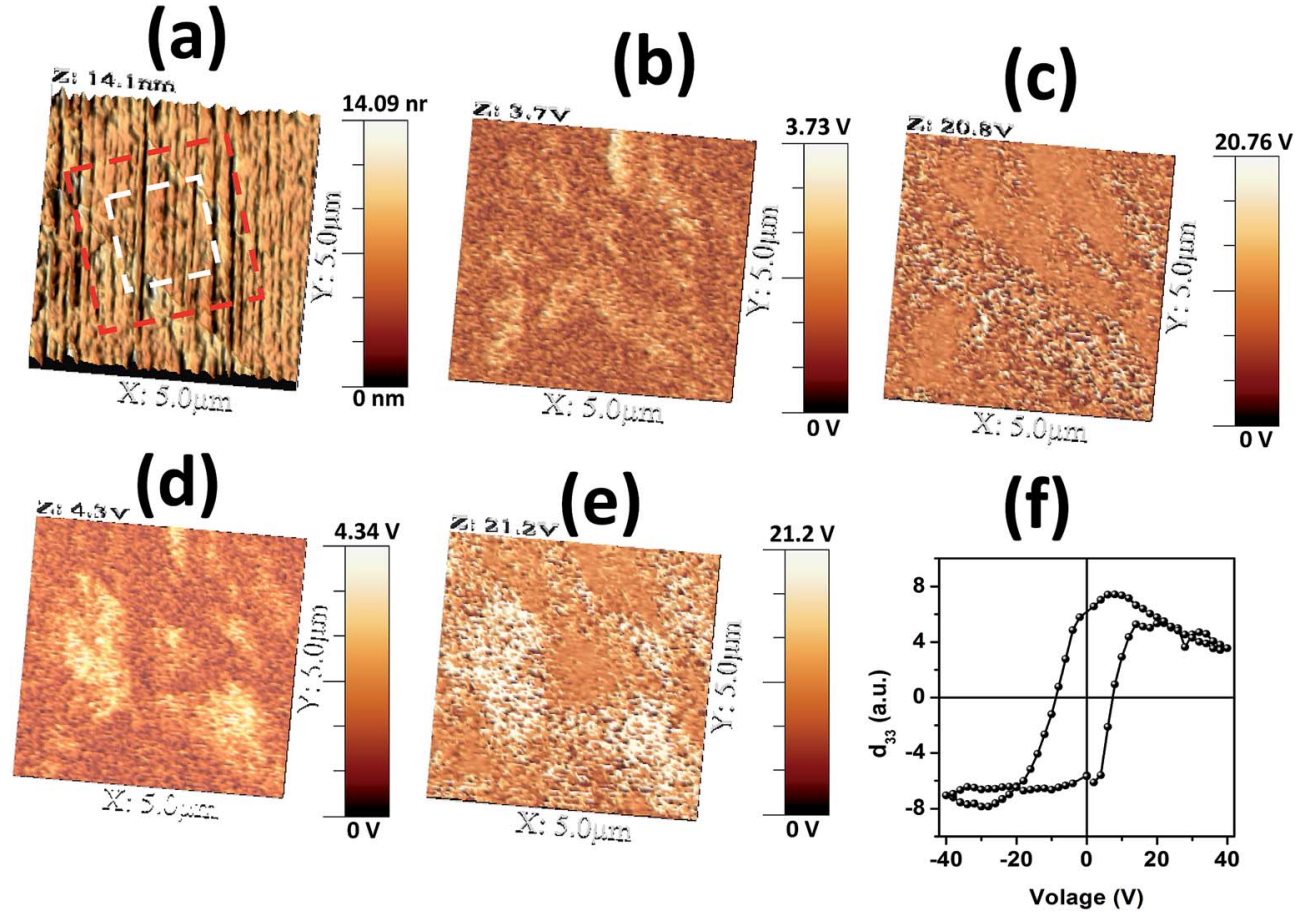

Fig. 10 Local PFM images of SBVT. (a) Topography, (b and d) amplitude piezoresponse before and after local poling, (c and e) phase piezoresponse before and after poling. (f) Piezoresponse hysteresis loop.

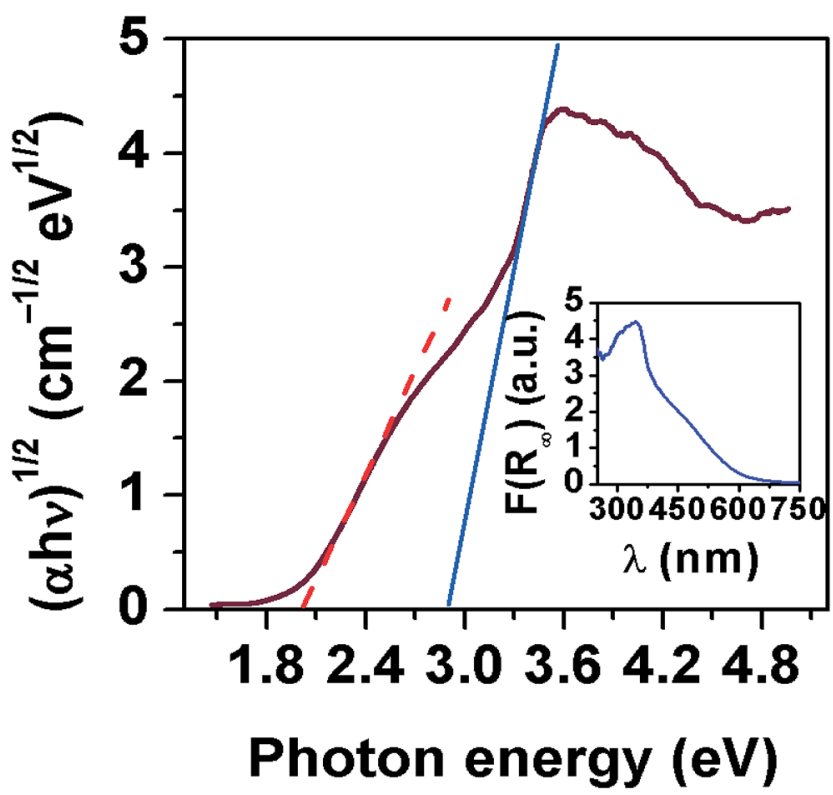

Fig. 11 Kubelka-Munk elaboration versus photon energy according to the indirect $E_{\mathrm{g}}$ model $(\gamma=2)$. The blue line and the dashed red line represent the $x$-axis intercept of the line that is tangent to the inflection points of the curve (i.e. apparent optical indirect $E_{\mathrm{g}} s$ as calculated using the Tauc procedure). In the inset is reported the DRS spectrum of SBVT.

that was already determined via optical spectroscopy, $E_{0}$ is a scale factor, equal to $-4.5 \mathrm{eV}$ for the NHE, $\chi_{\mathrm{A}_{a} \mathrm{~B}_{b} \mathrm{C}_{c}}$ is the absolute electro-negativity of compound $\mathrm{A}_{a} \mathrm{~B}_{b} \mathrm{C}_{c}$ which can be calculated by the formula: ${ }^{63} \chi_{\mathrm{A}_{a} \mathrm{~B}_{b} \mathrm{C}_{c}}=\left(\chi_{\mathrm{A}}{ }^{a} \times \chi_{\mathrm{B}}{ }^{b} \times \chi_{\mathrm{C}}{ }^{c}\right)^{\frac{1}{a+b+c}}$ where $\chi_{\mathrm{A}}$ is the Pearson's absolute electronegativity of element A. From these calculations, we obtained that the VB maximum of our SBVT is located at $2.87 \mathrm{eV}$, and consequently, we can represent the band structure of SBVT, together with the interband transitions due to Sm and V, in Scheme 1.

From these findings, the synthesized SBVT, absorbing indeed visible-light, can be used as a visible-light driven photocatalyst.

PCA results in the gas-solid phase are shown in Fig. 12(a) and (c). In dark conditions, there is no degradation of the pollutant gases. After the equilibrium into the reacting system was reached, and the PC reaction was enabled to start, we observe a clear decrease in the $\mathrm{NO}_{x}$ concentration. After $60 \mathrm{~min}$ irradiation time, the SBVT specimen degraded $12 \%$ of the starting $\mathrm{NO}_{x}$ amount. The mild PCA of SBVT specimen might be mainly due to its low SSA, that was estimated to be $1.2 \pm 0.1 \mathrm{~m}^{2}$ $\mathrm{g}^{-1}$. Also, from the sorption isotherms, Fig. 12(d), we know that the material is a mesoporous material, being the isotherm of type IV, and the presence of no micropores was detected ( $t$-plot, inset of Fig. 12(d)).

To check the stability and reusability of the sample, PC tests were repeated using the same specimen and protocol as in the first test. Results (for the first $20 \mathrm{~min}$ of reaction), are shown in Fig. 12(b) and Table 5. In these, PCA results are given as the apparent pseudo-first order rate constant, $k_{\text {app }}^{\prime}$. This was done because it is now well established that PC degradation rate obeys Langmuir-Hinshelwood kinetics: ${ }^{64} \ln \left(\frac{C_{0}}{C}\right)=k_{\text {app }}^{\prime} \times t$, where $C_{0}$ is the initial $\mathrm{NO}_{x}$ concentration, $C$ is the $\mathrm{NO}_{x}$ concentration at time $t$, and $k_{\text {app }}^{\prime}$ is the apparent pseudo-firstorder rate constant. The linear plot between $\ln \left(C_{0} / C\right)$ and 


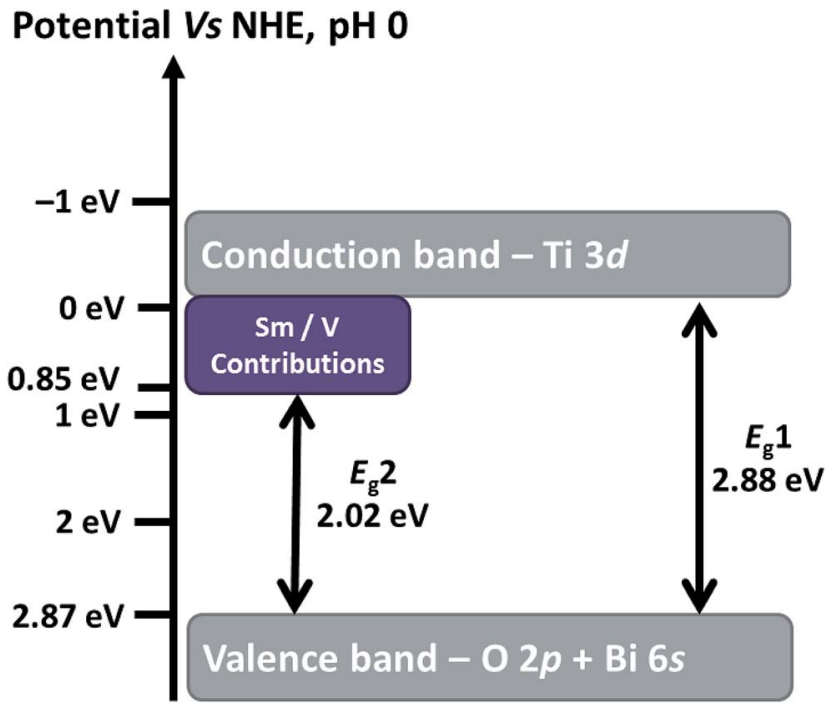

Scheme 1 Band structure of SBVT, relative to NHE at pH 0. The interband transitions, due to Sm and V, are also reported.

irradiation time $(t)$ reveals the PC reaction to follow pseudo-first order kinetics.

As depicted in Fig. 12 and Table 5, SBVT showed itself to be a very stable and reusable photocatalyst. A further proof of the stability of the SBVT as photocatalyst is given by their XRD patterns, recorded before and after five consecutive photocatalytic runs. As it is shown in Fig. 12(c), SBVT did not display any impurity due to decomposition, nor phase separation, this clearly reveals that neither photo-corrosion, nor photo-leaching happened during $\mathrm{NO}_{x}$ degradation; furthermore, the specimen also kept its crystallinity after five photocatalytic tests. This confirms the stability and durability of the catalyst under those experimental conditions.

As Dong et al. ${ }^{65,66}$ based on electron spin resonance (ESR), have identified $\mathrm{O}_{2}{ }^{--}$being the main active reactive oxygen species (ROS) responsible for the reduction of NO, a mechanistic insight of the $\mathrm{NO}_{x}$ photodegradation can be proposed as follows, when visible-light reaches the surface of SBVT specimen:

$$
\begin{gathered}
\mathrm{SBVT}+h \nu \rightarrow \mathrm{e}_{\mathrm{CB}}{ }^{-}+\mathrm{h}_{\mathrm{VB}}{ }^{+} \\
\mathrm{e}_{\mathrm{CB}}{ }^{-}+\mathrm{O}_{2} \rightarrow \mathrm{O}_{2}^{\cdot-} \\
\mathrm{NO}+\mathrm{O}_{2}^{\cdot-} \rightarrow \mathrm{NO}_{3}^{-} \\
\mathrm{NO}_{3}^{-}+\mathrm{H}^{+} \rightarrow \mathrm{HNO}_{3}
\end{gathered}
$$

On the other hand, photo-generated holes might also react with water molecules adsorbed on the surface of SBVT, giving:

$$
\begin{gathered}
\mathrm{h}_{\mathrm{VB}}^{+}+\mathrm{H}_{2} \mathrm{O}_{(\mathrm{ads})} \rightarrow \mathrm{OH}^{\cdot}+\mathrm{H}^{+} \\
\mathrm{h}_{\mathrm{VB}}{ }^{+}+\mathrm{OH}^{-} \rightarrow \mathrm{OH}^{\cdot} \\
\mathrm{NO}+\mathrm{OH}^{\cdot} \rightarrow \mathrm{NO}_{2}+\mathrm{H}^{+}
\end{gathered}
$$
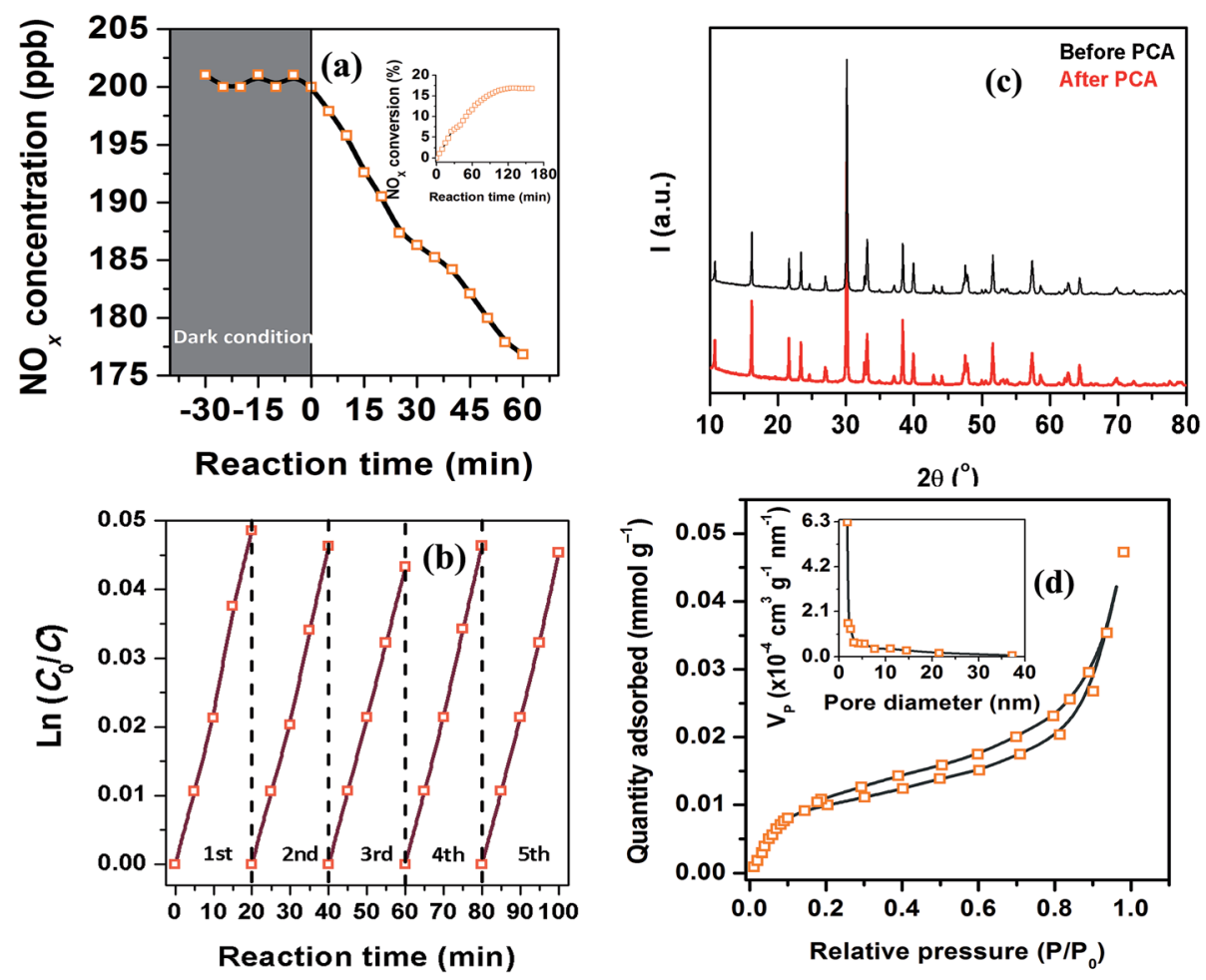

Fig. 12 (a) Photocatalytic $\mathrm{NO}_{x}$ abatement of SBVT, up to 60 min solar-light irradiation time. Inset: photocatalytic $\mathrm{NO}_{x}$ abatement of SBVT, up to 160 min solar-light irradiation time. (b) PCA results of SBVT repeated five consecutive times, shown as a plot of $\ln \left(C_{0} / C\right)$ as a function of the irradiation time $(t)$. (c) XRD patterns of SBVT before and after five consecutive photocatalytic $\mathrm{NO}_{x}$ abatement cycles. (d) Sorption isotherms of SBVT, of type IV. Inset: pore-size distribution. Here $V_{P}$ corresponds to pore volume. 
18 Z. Dai, F. Qin, H. Zhao, J. Ding, Y. Liu and R. Chen, ACS Catal., 2016, 6, 3180-3192.

19 H. Shi, H. Tan, W.-b. Zhu, Z. Sun, Y. Ma and E. Wang, J. Mater. Chem. A, 2015, 3, 6586-6591.

20 W. Zhao, Z. Jia, E. Lei, L. Wang, Z. Li and Y. Dai, J. Phys. Chem. Solids, 2013, 74, 1604-1607.

21 Y. Liu, M. Zhang, L. Li and X. Zhang, Appl. Catal., B, 2014, 160-161, 757-766.

22 X. Li, Z. Zhu, F. Li, Y. Huang, X. Hu, H. Huang, R. Peng, X. Zhai, Z. Fu and Y. Lu, Sci. Rep., 2015, 5, 15511.

23 A. H. Mamaghani, F. Haghighat and C.-S. Lee, Appl. Catal., B, 2017, 203, 247-269.

24 N. Imanaka and T. Masui, Appl. Catal., A, 2012, 431-432, 1-8.

25 World Health Organization, WHO guidelines for indoor air quality: selected pollutants, WHO Regional Office for Europe, Denmark, 2010.

26 A. C. Larson and R. B. Von Dreele, General structure analysis system (GSAS), National Laboratory Report LAUR, Los Alamos, 2004.

27 B. H. Toby, J. Appl. Crystallogr., 2001, 34, 210.

28 O. Hertel and M. Evan Goodsite, in Air Quality in Urban Environments, The Royal Society of Chemistry, 2009, vol. 28, pp. 1-22.

29 D. M. Tobaldi, R. C. Pullar, R. Binions, A. Belen Jorge, P. F. McMillan, M. Saeli, M. P. Seabra and J. A. Labrincha, Catal. Sci. Technol., 2014, 4, 2134-2146.

30 D. M. Tobaldi, R. C. Pullar, L. Duraes, T. Matias, M. P. Seabra and J. A. Labrincha, CrystEngComm, 2016, 18, 164-176.

31 F. L. Toma, G. Bertrand, D. Klein and C. Coddet, Environ. Chem. Lett., 2004, 2, 117-121.

32 C. H. Hervoches and P. Lightfoot, Chem. Mater., 1999, 11, 3359-3364.

33 W. Dollase, J. Appl. Crystallogr., 1986, 19, 267-272.

34 K. Momma and F. Izumi, J. Appl. Crystallogr., 2008, 41, 653658.

35 W. H. Baur, Acta Crystallogr., Sect. B: Struct. Crystallogr. Cryst. Chem., 1974, 30, 1195-1215.

36 K. Robinson, G. V. Gibbs and P. H. Ribbe, Science, 1971, 172, 567-570.

37 H. Du, S. Wohlrab and S. Kaskel, J. Phys. Chem. C, 2007, 111, 11095-11103.

38 E. Venkata Ramana, M. P. F. Graça, M. A. Valente and T. Bhima Sankaram, J. Alloys Compd., 2014, 583, 198-205.

39 T. Hirata and T. Yokokawa, Solid State Commun., 1997, 104, 673-677.

40 P. R. Graves, G. Hua, S. Myhra and J. G. Thompson, J. Solid State Chem., 1995, 114, 112-122.

41 Y. H. Wang, C. P. Huang and Y. Y. Zhu, Solid State Commun., 2006, 138, 229-233.

42 J. Min Ku, K. Yong-Il, S. Jung Min and W. Seong Ihl, J. Phys. D: Appl. Phys., 2004, 37, 2588.

43 K. Liang, Y. Qi and C. Lu, J. Raman Spectrosc., 2009, 40, 20882091.

44 M. K. Jeon, Y.-I. Kim, S.-H. Nahm and S.-I. Woo, J. Korean Phys. Soc., 2004, 45, 1240-1243.
45 S. Kojima and S. Shimada, Phys. B, 1996, 219, 617-619.

46 C. H. Hervoches, A. Snedden, R. Riggs, S. H. Kilcoyne,

P. Manuel and P. Lightfoot, J. Solid State Chem., 2002, 166, 449.

47 J. Hou, S. Jiao, H. Zhu and R. V. Kumar, CrystEngComm, 2011, 13, 4735-4740.

48 H. Qi, Y. Qi and M. Xiao, J. Mater. Sci.: Mater. Electron., 2014, 25, 1325-1330.

49 H. Du, L. Tang and S. Kaskel, J. Phys. Chem. C, 2009, 113, 1329-1339.

50 C. W. Ahn, H. J. Lee, I. W. Kim, J. S. Lee and W. K. Lee, Ferroelectrics, 2006, 331, 129-134.

51 C. Q. Huang, M. Chen, R. F. Liu, X. A. Mei and J. Liu, Key Eng. Mater., 2012, 512-515, 1333-1336.

52 G. Viola, K. Boon Chong, M. Eriksson, Z. Shen, J. Zeng, Q. Yin, Y. Kan, P. Wang, H. Ning, H. Zhang, M. E. Fitzpatrick, M. J. Reece and H. Yan, Appl. Phys. Lett., 2013, 103, 182903.

53 E. Venkata Ramana, F. Figueiras, A. Mahajan, D. M. Tobaldi, B. F. O. Costa, M. P. F. Graca and M. A. Valente, J. Mater. Chem. C, 2016, 4, 1066-1079.

54 D. M. Tobaldi, M. P. Seabra, G. Otero-Irurueta, Y. R. de Miguel, R. J. Ball, M. K. Singh, R. C. Pullar and J. A. Labrincha, RSC Adv., 2015, 5, 102911-102918.

55 F. E. Oropeza, I. J. Villar-Garcia, R. G. Palgrave and D. J. Payne, J. Mater. Chem. A, 2014, 2, 18241-18245.

56 C. Suzuki, J. Kawai, M. Takahashi, A.-M. Vlaicu, H. Adachi and T. Mukoyama, Chem. Phys., 2000, 253, 27-40.

57 H. Gu, D. Bao, S. Wang, D. Gao, A. Kuang and X. Li, Thin Solid Films, 1996, 283, 81-83.

58 J. Tauc, R. Grigorovici and A. Vancu, Phys. Status Solidi B, 1966, 15, 627-637.

59 K. A. Michalow, D. Logvinovich, A. Weidenkaff, M. Amberg, G. Fortunato, A. Heel, T. Graule and M. Rekas, Catal. Today, 2009, 144, 7-12.

60 A. S. Marfunin, Physics of minerals and inorganic materials : an introduction, ed. A. S. Marfunin, N. G. Egorova and A. G. Mishchenko, Springer-Verlag, Berlin, New York, 1979.

61 W. Wei, Y. Dai and B. Huang, J. Phys. Chem. C, 2009, 113, 5658-5663.

62 R. G. Pearson, Inorg. Chem., 1988, 27, 734-740.

63 Y. Xu and M. A. A. Schoonen, Am. Mineral., 2000, 85, 543556.

64 Y. Paz, in Photocatalysis: fundamentals and perspectives, The Royal Society of Chemistry, 2016, pp. 80-109, DOI: 10.1039/9781782622338-00080.

65 F. Dong, Z. Zhao, Y. Sun, Y. Zhang, S. Yan and Z. Wu, Environ. Sci. Technol., 2015, 49, 12432-12440.

66 F. Dong, Z. Wang, Y. Li, W.-K. Ho and S. C. Lee, Environ. Sci. Technol., 2014, 48, 10345-10353.

67 Y. Ohko, Y. Nakamura, A. Fukuda, S. Matsuzawa and K. Takeuchi, J. Phys. Chem. C, 2008, 112, 10502-10508.

68 T. Ibusuki and K. Takeuchi, J. Mol. Catal., 1994, 88, 93102. 